University of Zurich

Department of Economics

Working Paper Series

ISSN 1664-7041 (print)

ISSN1664-705X(online)

Working Paper No. 23

\title{
Auctions vs Negotiations in Public Procurement Which Works Better?
}

Rafael Lalive and Armin Schmutzler

August 2011 


\title{
Auctions vs Negotiations in Public Procurement Which Works Better?
}

\author{
Rafael Lalive and Armin Schmutzler*
}

Version: August 8, 2011

\begin{abstract}
Public agencies rely on two key modes to procure goods and services: auctions and direct negotiations. The relative advantages of these two modes are still imperfectly understood. This paper therefore studies public procurement of regional passenger railway services in Germany, where regional agencies can use auctions and negotiations to procure regional passenger rail services. This offers the unique opportunity to assess the two procurement modes within the same institutional and legal framework. We first characterize the decisions of the agency in a simple reduced form framework of negotiations and auctions. This analysis suggests accounting for the endogeneity of the choice of procurement mode by estimating the mode of procurement, quantity and price simultaneously. We then test this framework using information on lines that were auctioned and lines that were directly negotiated with the former monopolist. Results indicate (i) endogeneity of procurement choice can be fully characterized by observed line characteristics; (ii) frequency of service is 16 percent higher on lines that were auctioned compared to lines that were negotiated, and (iii) the procurement price is 25 percent lower on auctioned lines than on those with direct negotiations. Taken together, these results indicate a significant efficiency enhancing effect of auctions.
\end{abstract}

Keywords: Auctions, negotiations, liberalization, passenger railways, public procurement

JEL Classification: D43,D44,R48

*Rafael Lalive: University of Lausanne, CESifo and IZA; Rafael.Lalive@unil.ch. Armin Schmutzler: University of Zürich and CEPR; armin.schmutzler@econ.uzh.ch. We are grateful to Yeon-Koo Che, Phillippe Gagnepain, David Genesove, Michelle Goeree, Ali Hortacsu and Marc Ivaldi and to seminar audiences in Bern, Copenhagen (CIE), Tel Aviv (CEPR Applied IO meeting) and Zurich for helpful discussions. We would like to thank Felix Berschin who provided data on procurement prices and institutional knowledge. Susan Mendez and Andràs Pechy provided careful research assistance. 


\section{Introduction}

The nature of public procurement has changed dramatically over the last three decades. Until the nineteen eighties, there was widespread agreement that the state had a substantial role to play, not only in the financing, but also in the provision of many goods. Most importantly, network industries such as electricity, gas, water, railways and postal services were run as state monopolies in many countries. The wave of privatization and deregulation in the nineteen eighties led to institutional change all over the world, in industrialized as well as in developing countries. The retreat of the state and the introduction of competition were meant to foster efficiency and help to reduce taxes. Yet, the economic case for these policy measures is not as obvious as the early enthusiasm might suggest. Even though reasonable arguments can be made for privatization and competition, neither of these measures is necessarily efficiency-enhancing.

In the following, we focus on the effects of competition in public procurement. Understanding the role of competition in public procurement is important. Auctions and negotiations are the two key forms of public procurement of goods and services. Yet it is not clear which of the two modes dominates. There are at least two reasons why procurement auctions might lead to lower costs than direct negotiations with an incumbent supplier. First, competition puts pressure on firms to enter low bids; second, it helps to select the most efficient supplier. ${ }^{1}$ However, there are also countervailing effects. Bidder collusion may reduce the pressure on firms to submit aggressive bids, so that competitive bidding need not always reduce prices. Moreover, it is even possible that competition leads to higher prices: In common-value environments, increased fear of the winner's curse may induce less aggressive bidding in procurement auctions, potentially leading to higher procurement costs than direct negotiations. ${ }^{2}$ On a priori grounds, it is thus not evident whether procurement auctions lead to lower prices than negotiations. Moreover, as we will argue in more detail below, the empirical evidence on the relative advantage of the two means of public procurement is mixed.

This paper compares procurement auctions with direct negotiations. We analyze the effects of competition on the procurement of passenger railway services by public agencies in Germany. As a consequence of the railway reforms in the nineteen nineties, the sector has been gradually liberalized in many European countries. This has led to the coexistence of competitive procurement and direct negotiations with the incumbent, sometimes even within countries. Germany is a case in point. In January 1996, the German Regionalisierungsgesetz came into effect. This law stipulates that state agencies are responsible for the assignment of public funds to individual lines; and they can procure the services using direct negotiations with the dominant supplier $D B$ Regio or via auctions. ${ }^{3}$

\footnotetext{
${ }^{1}$ Also, it has sometimes been argued that an obligation to use competitive procurement can help to fight corruption (e.g., Chong et al. forthcoming).

${ }^{2}$ Wilson (1992) and Bulow and Klemperer (2002) provide related results for sales auctions.

${ }^{3}$ The law also specifies that the lion's share of regional passenger transport expenses is financed by the federal government. The federal government has distributed approximately 7 billion Euros per year to the 16 state governments since 1996 . The
} 
This setting provides the unique opportunity to compare the performance of competitively procured lines and lines on which the service levels and prices resulted from negotiations. Our main focus is on the frequency of service provided on regional passenger lines and on the transfers paid by the agencies for the provision of the railway services. Two specific aspects of the German railway system make the empirical analysis particularly interesting. First, because of the special role of $D B$ Regio it is not clear a priori that competition leads to lower procurement prices. While competitive procurement usually concerns individual lines or small networks, the direct negotiations with $D B$ Regio are about a large chunk of the services in the state under consideration (usually more than 50\%). It is therefore conceivable that direct negotiations lead to lower prices because they allow economies of scale to be exploited. Moreover, one of the potential bidders (DB Regio) is closely linked to the main input supplier, $D B$ Netz, the dominant network operator. ${ }^{4}$ All firms who use the network have to pay access prices to the infrastructure supplier. In the period we analyzed $D B$ Netz was free to design the access price system, subject to the control of the competition authority. It is conceivable in principle that it could have used this system in a way that weakens competitors, thus allowing DB Regio to maintain its dominant position without pricing too aggressively.

The fact that regional train services were procured both via direct negotiations and competitive auctions provides for an empirical design that allows studying the relative efficiency of these two procurement modes. The analysis pays particular attention to the fact that identifying the effects of competition is challenging because the procurement mode is not necessarily random: Whether a line is procured via auctions or via direct negotiations with the incumbent supplier is the outcome of the interaction between the agencies and the railway companies, in particular, the dominant supplier $D B$ Regio. It is therefore potentially problematic to use the mode of procurement as an explanatory variable. We address the potential endogeneity of procurement mode in two ways. First, we develop a simple model which jointly explains the decision on the procurement mode and the quantity procured. We assume that the agency and the incumbent supplier first negotiate over the mode and then, if the line is not procured competitively, on the quantity supplied by the incumbent. We model the result of the negotiation on quantity as the outcome of the maximization of a weighted average of the agency payoff (consumer surplus minus transfer payments) and the incumbent's profits. ${ }^{5}$ If there is competitive procurement, the agency sets the quantity itself (without negotiating with the incumbent), based on expectations on the transfer payment to the winner of the auction. Finally, like the quantity negotiations, the decision on the procurement mode is assumed to maximize the weighted average of the payoffs of the agency and the incumbent. The theoretical analysis can be translated into an empirical framework that models the choice of procurement mode, frequency of service, and procurement prices. This model can then

money is earmarked for public transport, and the lion's share (about $75 \%$ ) is used directly to pay train operators that run regional passenger services (Brenck and Peter 2007). DB Regio is a subsidiary of Deutsche Bahn AG, the successor of the former state monopolist.

${ }^{4}$ Like DB Regio, DB Netz is a subsidiary of Deutsche Bahn AG.

${ }^{5}$ One can also think of the optimization problem as reduced form of a lobbying game à la Grossman and Helpman (1994); then the weight on producer surplus reflects to which extent the agency is susceptible to influence activities (lobbying payments) of the firm. 
be used to test for endogeneity of procurement choice.

We address endogeneity of procurement mode choice by assembling a uniquely informative data set. This set contains information on the frequency of service on the line before the reform was enacted, as well as detailed indicators that capture the type of traction and indicators for service demand such as remoteness and population. The data allows addressing endogeneity with respect to important observed characteristics of the lines. Specifically, we use self-collected data on the frequency of service in 1993/4 (when the reform was not yet effective) and for 2003/4 (after a significant amount of lines had been procured using auctions) to assess whether auctions improve the frequency of service. We also obtained detailed information on winning prices for about $50 \%$ of the lines that were auctioned. Moreover, we construct prices that would have resulted from direct negotiations based on line-by-line information on the access prices for individual lines and regional averages of the procurement prices negotiated between the agency and the incumbent.

The empirical analysis uncovers three main findings. First, regional passenger service agencies used auctions predominantly on remote lines that were not very frequently served before the reform. Yet once we condition on observed characteristics, we find no difference in the pre-reform frequency of service between lines to be auctioned and lines that were negotiated with the incumbent. This means that there are no time-invariant predictors of service level that are correlated with procurement mode. Moreover, results of a model that allows testing for endogeneity of procurement mode with respect to unobserved characteristics also rejects the presence of endogeneity. This means that the railway reform in Germany created a quasiexperimental design that allows assessing the relative importance of auctions and negotiations.

Second, results suggest that the frequency of service on lines that were procured by auctions is 16 percent higher than the frequency of service on lines where the quantity was directly negotiated with the incumbent supplier. This remains true even if one controls for the endogeneity of procurement. Moreover, when we allow for selection of lines based on unobserved cost or surplus components, we find such selection not to be empirically important.

Third, results show that the procurement price is 25 percent lower on lines that were auctioned compared with those procured in direct negotiations. This suggests that auctions indeed improve efficiency of procurement of regional passenger railway lines. Auctions reduce the prices that the agencies have to pay for any given service level on a particular line. Since agencies have a fixed overall budget, they ask for higher service levels on the comparatively cheap lines that are procured using auctions.

We also show how these reduced form results can be interpreted in the light of the structural model of choice of procurement mode. We estimate the incumbent firm's say at the bargaining table, and the net surplus on lines as a function of procurement mode. We find that the incumbent exerts some influence on the quantity procured in negotiations. In the model, bargaining power acts as though it reduced the price per train kilometer provided. As a result of this, regional passenger trains run $17 \%$ more frequently than would be optimal given the high transfer price in negotiations. Negotiations produce a sub-optimally high frequency of service, i.e. the service level is higher than the one that maximizes net consumer surplus. 
Moreover, we use the parameters of the consumer surplus function on which the agency bases its optimization to calculate effects on net consumer surplus. We find that auctions increases net surplus by 29 percent of the transfer payments under negotiation (or by 4 percent of net surplus) with reductions in transfer payments contributing more than half of the increase in net surplus. Auctions eliminate the incumbent's say in setting the frequency of service and they reduce the transfer price. We find that the reduction in the transfer price is more important in increasing net surplus than eliminating the bargaining power of the incumbent. These findings highlight the efficiency-enhancing effects of auctions through reductions in procurement prices.

The remainder of the paper is organized as follows. Section 2 summarizes related literature, and Section 3 discusses the institutional background. In Section 4, we develop a simple theoretical framework to describe procurement choice; we then provide an empirical specification in Section 5. Section 6 describes the data set. In Section 7, we present our results. Section 8 concludes.

\section{Related Literature}

This paper is related to several strands of the literature. The first strand discusses the relative efficiency of auctions and negotiations. The second strand discusses railway reforms. We provide a short summary of these two strands of the literature below.

Auctions vs. Negotiations: The literature has focused on the pros and cons of auction mechanisms, and it has identified circumstances under which procurement auctions are preferable to negotiations, either from the perspective of the buyer or from a broader efficiency perspective. These normative conclusions have also guided the search for positive results: It is often argued that the circumstances under which auctions are chosen by unconstrained buyers are those under which the advantages of auctions are pronounced.

The normative literature has first considered the problem of sales mechanisms. For instance, Bulow and Klemperer (1996) give general conditions under which adding a competitor to an optimal sales mechanism with $n$ buyers improves the outcome for the seller, and, in particular, auctions are preferable to negotiations. Applied to a procurement context, the result identifies the circumstances under which, from the perspective of the agency, competitive procurement is favorable to negotiations with a single supplier, no matter how cleverly these negotiations are designed.

With common or affiliated values, it is well-known that, because of fear of the winner's curse, rational bidders will bid less aggressively when the number of bidders increases. As a result, in spite of increasing competitive pressure, the equilibrium bids need not be monotone decreasing in the number of bidders. ${ }^{6}$ Applied to the procurement context, procurement costs are not necessarily decreasing in the number of firms, and not even necessarily lower with competitive bidding than with direct negotiations. Empirical evidence supports this idea. Hong and Shum (2002) use data from procurement auctions carried out by the New Jersey Department of Transportation between 1989 and 1997. They argue that both private-value and

\footnotetext{
${ }^{6}$ See, for instance, the examples of Wilson (1992) for the first-price sealed-bid sales auctions, and the analysis of Bulow and Klemperer (2002) for ascending bid auctions.
} 
common-value components are present for highway-work and bridge-repair auctions, whereas road paving contracts typically only exhibit private value components. For the auctions with common-value components, their analysis suggests that procurement costs are lowest with three bidders, so that unlimited competition is not necessarily advantageous for the agency.

Another reason why price advantages from competitive procurement cannot be taken for granted is collusion. Bidding rings in auctions have been analyzed theoretically by Mc Afee and Mac Millan (1992), and they have been detected frequently in the context of procurement. While collusion between bidders does not necessarily prevent the efficient allocation of the task, it reduces competitive pressure on prices.

Manelli and Vincent (1995) have highlighted the potential disadvantages of auctions when the buyer has preferences for both high quality and low procurement costs; such disadvantages are also a common concern of procurement agencies.

Extending the work of Goldberg (1977), Bajari and Tadelis (2001) have emphasized the role of ex-post transaction costs: For instance, in highway construction projects, there will often be exogenous uncertainty about the precise nature of the task. As a contractor engages in the project, he will learn about the best way to carry it out. This may make major design changes desirable from an efficiency perspective and hence necessitate renegotiations - but with competitive procurement, this is potentially more difficult than with direct negotiations. ${ }^{7}$ Using data for highway contracting in Northern California from 1995 to 2001, Bajari et al. (2009) indeed confirm that auctions induce bidders to take ex-post transaction costs into account when casting their bids, potentially leading to higher payments of the agency than direct negotiations.

Building from the normative literature that discussed the relative merits of auctions and negotiations, a small group of authors has taken a more positive approach, trying to identify the circumstances under which auctions are more likely to be chosen. For instance, Bajari et al. (2009) show that auction mechanisms tend to be used when the number of potential bidders is sufficiently high, whereas buyers resort to negotiations when projects are complex and when they face reputable and experienced sellers. ${ }^{8}$ Based on a data set of all public building procurement contracts in France in 2007, Chong et al. (2010) identify a similar role of complexity. However, their result only holds for local buyers, not for central buyers. Also, the result is not robust to modified measures of complexity. ${ }^{9}$

The fact that procurement decisions depend on project characteristics suggests that a comparison of auctions and negotiations needs to take the potential endogeneity of the decision into account. We take this issue seriously and provide a simple model of procurement choice and resulting quantity outcomes. We are not

\footnotetext{
${ }^{7}$ The authors argue specifically that, with procurement auctions, it is more natural to use fixed-price rather than cost-plus contracts, and that fixed price contracts make renegotiation difficult.

${ }^{8} \mathrm{On}$ a related note, Banerjee and Duflo (2000) have shown in a private procurement setting that seller reputation makes cost-plus contracts more likely.

${ }^{9}$ The authors' preferred measure of complexity is a dummy "taking the value 1 when the public works involve the construction of infrastructure and specialized works involving some civil engineering, as opposed to more generic works like installation of a door or a window, or the construction of office spaces." The authors also use contract duration, the number of sub-contractors and the value of the contract.
} 
aware of any papers that do so for the comparison between procurement auctions and negotiations. Gagnepain and Ivaldi (2010) have considered the related decision between cost-plus and fixed price contracts, using data from the French public transportation sector. ${ }^{10}$ Like us, they consider situations where the decision may reflect lobbying of the firms. Compared to Gagnepain and Ivaldi who consider non-competitive procurement, we focus on the potential endogeneity of procurement mode. It turns out that variables that might affect the quantity might also affect the procurement mode. This is interesting from a theoretical point of view, and it also helps to guide the empirical analysis. ${ }^{11}$

Railway Reforms: Apart from contributing to the literature on auctions vs. negotiations, the paper also sheds light on the evaluation of the railway reforms that were introduced in Europe in the nineteen nineties. There is a limited number of empirical contributions on this subject. Several papers deal with the efficiency effects of various reforms in an international context on an aggregate level (Cantos et al. 1999, Friebel et al. 2010), emphasizing the role of cross-country institutional differences. Friebel et al. identify positive efficiency effects of deregulation. Other authors resort to before-and-after comparisons in individual countries. For instance, Cowie (2002) and Pollitt and Smith (2001) analyze the outcomes of the U.K. reform, coming to more positive conclusions than the political debate in the U.K. would suggest.

Contrary to these earlier contributions, our paper allows the comparison of different institutions within one country, without relying on a before-and-after comparison. Also, it focuses on a specific aspect of the reform (competitive procurement) which has been important in several other countries as well. ${ }^{12}$

The paper that comes closest to ours is Lalive and Schmutzler (2008). There, we considered a much smaller sample of railway lines (for Baden-Württemberg, one of the 16 German states). Using a differencein-difference approach, we established a positive relation between competition and the frequency of service. However, the present paper differs substantially from its precursor in at least four important dimensions. First, the data set for the analysis was limited to one region of Germany. We provide an analysis for all regional passenger railways services in this paper. Second, without an appropriate framework for dealing with the procurement mode decision, we could not adequately discuss the problem of endogeneity of procurement choice. Third, because we did not have any procurement price data, we could not identify what exactly the source of any causal relation between competition and service quality might be. For instance, our earlier analysis did not preclude the possibility that competitively procured lines enjoy higher service levels merely because agencies systematically spent more money on them than on the remaining lines. Finally, the analysis lacked a structural model and therefore did not contain an explicit discussion of incumbent power and net surplus effects. ${ }^{13}$

\footnotetext{
${ }^{10}$ In a related paper on this industry, Gagnepain et al. (2010) analyze a model where the type of the contract (cost-plus or fixed-price) can be renegotiated. They find substantial welfare costs of renegotiation.

${ }^{11}$ There is also a broadly related literature on policy endogeneity that does not deal specifically with competitive procurement (Besley and Case 2006, Duso and Röller (1997), Krozner and Strahan (1999)).

${ }^{12}$ The most prominent examples are the United Kingdom and Sweden, but several other European countries have followed suit.

${ }^{13}$ Beyond the railway sector, there is a substantial amount of (descriptive) evidence on competitive tendering in the bus
} 


\section{Regional Passenger Railways in Germany}

In most European countries, the railways were run by integrated state monopolies until the early nineteen nineties. ${ }^{14}$ In West Germany, Deutsche Bundesbahn owned most of the infrastructure and was the dominant operator for passenger and freight services. In addition, there were several minor railroad companies ( $N E$ Bahnen) that were typically also vertically integrated and carried out freight and/or passenger transportation on small networks. In East Germany, Deutsche Reichsbahn was the integrated operator of the railway system.

In response to the EU-directive 91/440, a major railway reform became effective in Germany on January 1, 1994. Deutsche Bahn AG became the successor of Deutsche Bundesbahn and Deutsche Reichsbahn. In addition, the reform had several elements that are important in the context of our analysis.

\subsection{Financing}

Before the reform, the railway system created large deficits. Local passenger transportation clearly was responsible for a large part of this deficit, but as the overall deficit was financed globally ex post, it was impossible to attribute the costs to specific lines. The reform changed the approach to financing passenger services radically. Whereas long-distance transportation is expected to be profitable, it is still taken for granted that the revenues from passenger service do not suffice to cover costs on the local passenger lines. However, the services that are expected and the payments that railway companies receive from the state are now specified contractually ex ante. Mainly to finance the services, the federal state has distributed a total of about 7 billion Euros per year since 1996 to the 16 states. The responsibility for the use of these funds (the so-called Regionalisierungsmittel) lies with the states.

\subsection{Vertical industry structure}

As a prerequisite for the introduction of competition, the incumbent firm Deutsche Bahn AG was reorganized. Two upstream subsidiaries (DB Netz for the network and DB Station \& Service for the stations) and three upstream subsidiaries (DB Regio for regional passenger transportation, DB Reise und Touristik for longdistance passenger services and DB Cargo for freight) were introduced. Thus, a move into the direction of vertical separation was made. ${ }^{15}$ Railway companies (including $D B$ Regio) that want to use the network of $D B$ Netz pay access charges. These are determined by DB Netz. ${ }^{16}$

industry, as surveyed by Hensher and Wallis (2005). The results are mixed, with reports of substantial efficiency gains in the early phase of the deregulation in London (White 2000), but essentially no effects in Italy (Boitani and Cambini 2006).

${ }^{14}$ This purely descriptive section has some overlap with Lalive and Schmutzler

${ }^{15}$ In 1999, this separation was taken one step further. Deutsche Bahn AG then became a holding company, consisting of five corporations.

${ }^{16}$ Until 1998, the access charges were linear. Then a system of non-linear prices was introduced that was abolished in 2001 , after the competition authority had declared that they constituted a misuse of a dominant position. DB Netz then returned to linear access charge. However, the charges were now regionally differentiated. In particular, lines in sparsely populated regions where subjected to higher access charges. 


\subsection{Auctions vs. Negotiations}

The 16 states have created agencies that organize the procurement process. ${ }^{17}$ These agencies receive a fixed budget for the procurement of railway services, but they have considerable freedom in the way that they procure services.

Direct negotiation with the incumbent supplier is still the dominant mode of procurement. The agencies have long-term contracts with $D B$ Regio that usually cover at least half of the regional passenger services. These contracts specify the expected service level over a period of 10-15 years and the payments that $D B$ Regio gets for its services. Also, the contracts typically contain clauses that regulate the speed with which competitive procurement is introduced.

Competitive procurement usually involves some kind of bidding procedure in which firms ask for transfer payments to carry out railway services. The successful bidder receives his required transfer and obtains the franchise for a period of typically around 10 years. In the simplest case, the agency specifies the frequency of service and detailed requirements about the service quality that it expects. The specifications include the rolling stock, the prices charged to customers, etc. ${ }^{18}$ The contract is awarded in a first-price sealed-bid auction, where the bids are the procurement prices. ${ }^{19}$ The winner then becomes the residual claimant for the operating profits of the line. ${ }^{20}$. In other cases, the agencies use multi-dimensional auctions where the bidders obtain scores for high quality as well as for low prices. ${ }^{21,22}$

The extent to which competitive procurement is used varies considerably across agencies, and so do the details of the procedure. In the period under consideration, agencies were essentially free to determine the procurement mode for any of the lines they serve. ${ }^{23}$ However, it has become a standard practice that the agency and the incumbent negotiate on which lines will be opened up to competition during the lifetime

\footnotetext{
${ }^{17}$ Many states have only one agency. In other states, there are several agencies; for instance, in Northrhine-Westphalia, there initially were nine different agencies. In 2010, 25 agencies are members of the umbrella organisation BAG-SPNV.

${ }^{18}$ In Germany, regional public transport organisations (Verkehrsverbünde) coordinate timetables, prices etc. on a substantial part of the network. In some cases, but by no means always, these organizations are identical with the agencies that procure services; often they are entirely separate institutions. Either way, the freedom of railway operators to set prices is limited by the existence of the public transport organizations. Similar restrictions apply to rolling stock which is usually tightly specified (Brenck and Peter 2007).

${ }^{19}$ In typical textbook treatments of competition for the market (Viscusi et al. 2000), the procedure is slightly different. Contractors do not bid the required subsidy. Instead, they bid the price they want to charge to consumers and the lowest bid wins (Demsetz 1968).

${ }^{20}$ This description corresponds to so-called net contracts. Alternatively, the agencies also use gross contracts where the agencies receive the revenues, but the firms are residual claimants of cost savings.

${ }^{21}$ See Che (1993) for a formal analysis of such auctions. However, the role of the quality dimension is often not made absolutely clear ex ante, so that the mechanism corresponds to a beauty contest.

${ }^{22}$ It appears plausible that the decision on the details of the auction is also influenced by the negotiations to some extent. For instance, the incumbent might lobby for the use of specific vehicles that it can supply more readily than the competitors. We abstract from this possibility to focus on the main margin of choice between auctions and negotiations.

${ }^{23}$ This right has been challenged both by national courts and the EU. This is leading to a clearer move into the direction of more competition (Brenck and Peter 2007).
} 
of the contract. ${ }^{24}$ The institutional structure and the history of regional passenger service provision make it likely that the incumbent interferes with this decision. DB Regio belongs to Deutsche Bahn AG whose other subsidiaries take decisions on such issues on infrastructure and long-distance travel which are of vital interests for many local states. Also, the incumbent can exert some pressure on the agency because it is a large public employer. ${ }^{25}$

\subsection{Types of Contracts}

Contracts are heterogeneous in several ways. First, contracts differ according to the treatment of fare revenues. In net contracts, the train operator receives the revenues, and the agency only pays the difference between revenues and costs. In gross contracts, the agency receives the revenues, whereas the operator receives a cost compensation. In addition, there are various hybrid forms which are essentially gross contracts with additional demand incentives. In our data set, $67 \%$ of competitive lines were procured in net contract. The grand contracts with $D B$ Regio are usually net contracts. ${ }^{26}$ We take this asymmetry between competition and direct negotiations into account in our estimation.

Second, there is the standard distinction between fixed price contracts and cost plus contracts. According to Brenck and Peter (2007), in a sample of contracts analyzed by Borrmann (2003), $40 \%$ of the contracts are fixed-price, whereas the rest contains cost-pass-through clauses for costs on which the operator has little influence such as energy costs and infrastructure charges. On a related note, the contracts typically contain dynamic adjustment formulas, at least for access charges. This reduces the need for renegotiation. Further, the contracts typically describe the conditions under which renegotiations are allowed and which form they should take (Brenck and Peter 2007).

Finally, the contracts contain various incentive elements to deal with failure to deliver the quality that was agreed upon; in some cases, the contracts also contain some elements of bonus payments (Brenck and Peter 2007).

\subsection{Evolution of the Market}

As a result of the introduction of competition for the market, the market share of $D B$ Regio's competitors has grown substantially. In 1994, the NE-operators had a market share of 3\% (based on train-km); in 2004, the share was $12 \%$ (Brenck and Peter 2007).

The pool of competitors consists of several types of firms. First, there are the above-mentioned pre-reform

\footnotetext{
${ }^{24}$ The most competition-friendly authority (LVS in Schleswig-Holstein) signed a long-term contract in 2003, according to which the last part of the network will be opened to competition in 2014, 20 years after the railway reform. (See http://www.premiumpresse.de/bahn-und-land-schleswig-holstein-unterzeichnen-verkehrsvertrag-PR156817.html, visited July 4, 2011.

${ }^{25}$ Moreover, in some cases, former $D B$ Regio employees making a career in the state and vice versa. For instance, Otto Wiesheu, one of the leading Bavarian politicians, became a member of the managing board of Deutsche Bahn in 2005.

${ }^{26}$ An exception is the state of Hessen (Berschin, private communication).
} 
NE-operators. Starting from their old infrastructure, they often have expanded their operations onto the network of Deutsche Bahn where they only provide the downstream services. ${ }^{27}$ Second, some companies have expanded their activities from other modes of public transportation into the railroad sector. Third, some new companies have been formed. ${ }^{28}$ Fourth, some railway operators are joint ventures between other companies, in some cases including DB Regio. ${ }^{29}$ Finally, foreign firms such as Connex, Arriva and Abellio have entered the market.

\section{Auctions vs Negotiations}

This section discusses a simple theoretical framework that explains why auctions are chosen in some cases, but not in others. This framework is essential to understand endogeneity of procurement choice. The model also explains the quantity of railway services procured.

\subsection{Overview}

Our model is designed to capture the salient features of regional passenger service procurement in Germany. The model involves two stages. In a first stage, there is a negotiation between the agency and the incumbent supplier that determines whether a line is procured in an auction or by direct negotiations with the supplier. The procurement mode is chosen that maximizes a weighted average of the expected payoffs of the agency and the incumbent, given both parties' expectations on payoffs under auctions and negotiations, respectively. Moreover, because auctions were a new procurement mode during the period under consideration, we assume the agency incurs a line- and agency-specific administrative cost to carrying out the auction. ${ }^{30}$

In the second stage, the quantity of regional passenger railway services is determined depending on the procurement mode that was chosen in the first stage. Quantity refers to the number of train kilometers provided on a line. Under negotiations, the quantity is determined as follows. The agency cares about net surplus, that is, consumer surplus net of transfer payments; the firm would like to maximize profits. ${ }^{31}$ Net surplus is maximal when the marginal additional surplus equals the procurement price. Yet since the transfer payment of the agency to the incumbent reflects both costs and a profit component, the incumbent would like the agency to expand the quantity of service beyond what is optimal for net surplus. We model this tension in the quantity negotiations by assuming that the negotiated quantity maximizes the weighted average between the incumbent's profit and the net surplus of the agency.

\footnotetext{
${ }^{27}$ Examples of pre-reform operators are Hessische Landesbahn (HLB), Regentalbahn (RAG), Südwestdeutsche Eisenbahngesellschaft (SWEG) and Württembergische Eisenbahngesellschaft (WEG).

${ }^{28}$ An example is the Prignitzer Eisenbahn in the state of Brandenburg.

${ }^{29}$ For instance, the Breisgau S-Bahn was founded jointly by SWEG and the Freiburger Verkehrs AG, the municipal transportation firm in Freiburg.

${ }^{30}$ Brenck and Peter (2007) cite an agency representative who estimates the administrative costs as 250,000 Euro to 400,000 Euro per tender.

${ }^{31}$ Here, net surplus should be interpreted broadly, including, for instance possible environmental benefits from railway services. These benefits are substantial (see Lalive et al. 2011).
} 
The agency sets a required quantity level on those lines where auctions are used. The auction then determines which firm wins the contract and what the procurement price is. The auction is not modeled explicitly. Instead, we assume that the agency and the incumbent have an expectation on the outcome of the auction. As to the agency, we suppose that it can form an expectation on the procurement price it will have to pay to the winning bidder. As discussed in Section 2, the agency might expect lower prices under auctions than under negotiations for at least two reasons. First, it should expect the costs of the winning bidder to be lower under auctions than under negotiations, reflecting a positive probability that the successful bidder can provide the services at lower costs than the incumbent. Second, it might expect competitive pressure to force all firms (including the incumbent) to bid closer to costs than under direct negotiations. The agency chooses quantity to maximize net surplus. This differs from the case where the agency negotiates the quantity with the supplier.

Even though we assume that the incumbent does not influence the quantity decision in the auction, its expectations on its profits in the auction do influence the outcome of the first stage negotiations regarding the procurement mode. These expectations concern both the probability that the incumbent wins the auction and the expected profits in case it is successful. It is likely that the incumbent prefers quantity negotiations to auctions, because there is a chance of losing in the auction and because it usually has to live with lower procurement prices to be successful. The agency would always prefer auctions to direct negotiations if the fixed cost of running the auction were zero. Whether the agency chooses auctions or negotiations therefore depends on the fixed cost, the gain in net surplus from choosing auctions and the incumbent's influence in the first stage negotiation.

\subsection{Details}

Let $D_{i} \in\{1,0\}$ denote the procurement mode for a particular railway line $i$, with 1 standing for auctions and 0 for negotiations. Let $q_{i}$ be the service level, that is, the quantity of railway services procured. Let $S_{i}\left(q_{i}\right)$ denote consumer surplus which is increasing in $q_{i}$.

\subsubsection{Negotiations}

For each unit of quantity supplied, the agent pays an amount of $t_{i}^{N}$ to the incumbent under negotiations. We will refer to $t_{i}^{N}$ as the procurement price henceforth. Note that the theoretical analysis takes the procurement price as exogenously given, but allows it to depend on specific characteristics of line $i$. The rationale for the exogeneity assumption is that we take prices as resulting from policies that are set at the national level by DB Regio, without flexibility at the local level. The empirical analysis will consider and estimate the main determinants of the procurement price.

The agency aims at maximizing net consumer surplus, $S_{i}\left(q_{i}\right)-t_{i}^{N} q_{i}$, but it is constrained by the firm's objective to maximize its own profits. These profits are a fraction $M_{i}^{N}$ of total transfer payments. The firm has a weight $\tau_{i}$ in the negotiations. Defining $P_{i}^{N} \equiv \tau_{i} M_{i}^{N}$ as an index of the incumbent's power in the 
negotiations, the quantity is thus determined as

$$
q_{i}^{N} \equiv \arg \max _{q_{i}}\left(S_{i}\left(q_{i}\right)-t_{i}^{N} q_{i}+P_{i}^{N} t_{i}^{N} q_{i}\right)
$$

This formulation immediately shows that, if the incumbent has a positive weight, it will lobby for higher quantities than the agency itself would consider optimal, because the incumbent obtains profits from supplying larger quantities. As long as one takes the procurement mode as given, bargaining power of the incumbent influences the quantity choice as though the agency were facing a lower procurement price. This leads to a situation where the quantity provided need not be low even though net consumer surplus is.

Surplus, procurement prices and power index are all potentially dependent on line characteristics. We shall explore this in the empirical analysis.

\subsubsection{Auctions}

Next, we summarize the assumptions on competitive procurement. We suppose that the agency $j(i)$ in charge of procuring the services on line $i$ can run a competitive procurement auction at an administrative cost $F_{i j}$; thus the cost is agency- and line-specific. If an auction mechanism is used, the agency determines a quantity $q_{i}$ that it plans to procure in the auction. We model the auction by stating assumptions on the expected procurement price and on the expected profits of the incumbent in case such an auction is carried out. These assumptions can be rationalized as the outcome of a first-price auction in which potentially heterogeneous firms submit bids which correspond to the procurement price. We assume that the agency knows sufficiently much about the bidders and their cost structures that it can form an expectation on the resulting transfer payments to the winning bidder. We denote the expected transfer payments per unit as $t_{i}^{A}$. As these expected payments are determined by primitives of the competitive environment, the agency takes them as given and determines the quantity as

$$
q_{i}^{A} \equiv \arg \max _{q_{i}}\left(S_{i}\left(q_{i}\right)-t_{i}^{A} q_{i}\right)
$$

Thus, there are two differences between auctions and negotiations. First, in negotiations the incumbent can influence the quantity chosen directly, and it benefits from higher quantity. Second, the transfer price potentially differs in auctions and negotiations. If auctions lower procurement prices, auctions will tend to lead to higher quantities. Note that it is not clear whether auctions or negotiations deliver higher quantities. Whereas negotiations increase quantity due to the incumbent's negotiation power, auctions increase quantities due to lower procurement prices. The net effect is unclear. Moreover, it is essential to assess the effect of auctions on prices to discuss the efficiency consequences of the choice of procurement mode.

\subsubsection{Choice of procurement mode}

The first stage negotiation concerns the choice of procurement mode. Similar to the choice of quantity under negotiation, we assume that the agency selects the procurement mode that maximizes net consumer surplus 
corrected for the incumbent's bargaining power and the fixed costs of setting up the auction.

The incumbent has no impact on the quantity chosen in the auction. Yet its expected profits in the auction affect the outcome of the first stage negotiations on the procurement mode. The incumbent expects a profit in the auction that is only a fraction of the total transfer payments $t_{i}^{A} q_{i}^{A}$ : First, he has to take into account that a large part of the transfer payments reflects the costs of running the service in case he is successful, leaving only some fraction $M_{i}^{A}$ per unit. Second, he will generally expect that a competitor wins the auction with some positive probability $r_{i}$. Thus the incumbent expects profits $r_{i} M_{i}^{A} t_{i}^{A} q_{i}^{A}$ if an auction takes place. Taking the firm's weight $\tau_{i}$ in the negotiation on procurement mode into account, we define $P_{i}^{A} \equiv \tau_{i} r_{i} M_{i}^{A}$ as an index of the incumbent's power in auctions: This index measures the incumbent's share of transfer payments obtained in auctions, weighted with its power in the negotiations in the procurement mode.

The agency chooses the procurement mode that maximizes consumer surplus corrected for the role of the incumbent. Thus, the agency chooses to procure using an auction if and only if

$$
S_{i}\left(q_{i}^{A}\right)-t_{i}^{A} q_{i}^{A}+P_{i}^{A} t_{i}^{A} q_{i}^{A}-F_{i j} \geqq S_{i}\left(q_{i}^{N}\right)-t_{i}^{N} q_{i}^{N}+P_{i}^{N} t_{i}^{N} q_{i}^{N}
$$

Why would an agency ever choose to negotiate directly with the incumbent? First, for the reasons mentioned in Section 2, it is not absolutely clear that the procurement prices under auctions are lower than under negotiations. Second, the agency might want to avoid the fixed cost of setting up the auction. Third, the incumbent might use his weight to lobby for negotiations because of the higher expected profits.

Equation (3) also helps to identify the circumstances under which auctions are more likely to be chosen. First, obviously high administrative costs work against auctions. Second, as long as the incumbent's power coefficients $P_{i}^{A}$ and $P_{i}^{N}$ are strictly smaller than 1 , decreases in transfer prices $t_{i}^{A}$ and increases in $t_{i}^{N}$ work in favor of auctions. We will assess empirically which line characteristics determine the relative procurement prices.

\section{Empirical Specification}

This section discusses how to structurally estimate the model of the previous section. We introduce functional forms for the surplus function, procurement prices and the power indices. These functional forms are used to derive the empirical function for quantity and to characterize procurement choice. Finally, we address endogeneity of procurement choice with a semi-parametric approach.

\subsection{Price and quantity equations}

We first discuss the functional form for procurement prices. We treat procurement prices in auctions and negotiations as functions of line characteristics $x_{i 1}, \ldots, x_{i I}$ measured in deviations from the sample mean. Define $x_{i}=\left(1, x_{i 1}, \ldots, x_{i I}\right)$. We suppose the procurement price under negotiations is given as $t_{i}^{N}=\exp \left(x_{i}^{\prime} \nu+\right.$ 
$\left.\epsilon_{i}^{\nu}\right)$, where $\nu=\left(v_{0}, v_{1}, \ldots, v_{I}\right)$ is a parameter vector to be estimated. This specification ensures that prices are non-negative and it provides a convenient log-linear characterization of the procurement prices. The specification allows for a systematic component of price $x_{i}^{\prime} \nu$ and an idiosyncratic component of price $\epsilon_{i}^{\nu}$.

To capture the idea that competitive procurement might affect the costs of the procuring firm as well as the markup and therefore influence procurement prices, we write $t_{i}^{A}=\exp \left(x_{i}^{\prime} \alpha+\epsilon_{i}^{\alpha}\right) t_{i}^{N}$ for the procurement price under auctions. $\alpha=\left(\alpha_{0}, \alpha_{1}, \ldots, \alpha_{I}\right)$ is a parameter vector to be estimated. Note, we model the effect of auctions on procurement prices using an exponential functional form, $\exp \left(x_{i}^{\prime} \alpha+\epsilon_{i}^{\alpha}\right)$. This is a flexible functional form that ensures that the auction procurement price stays positive. This functional form allows auctions to increase or decrease procurement prices.

Recall that $D_{i}=1$ if line $i$ was procured in an auction, and $D_{i}=0$ if line $i$ was procured in direct negotiation between the agency and the incumbent. We obtain the following empirical specification for the log procurement price:

$$
\log t_{i}=x_{i}^{\prime} \nu+\epsilon_{i}^{\nu}+D_{i}\left(x_{i}^{\prime} \alpha+\epsilon_{i}^{\alpha}\right)
$$

The coefficient $v_{0}$ captures the average procurement price for the lines that are not procured competitively; $v_{1}, \ldots, v_{I}$ capture the effects of line characteristics on the procurement price. Similarly, $\alpha_{0}$ captures the relation between prices under auctions and prices under negotiations for the average line in the sample: A value of 0 corresponds to no differences; negative values arise if the procurement prices for auctions are lower on average than for negotiations; $\alpha_{1}, \ldots, \alpha_{I}$ capture the effects of line characteristics on the relative procurement prices.

Second, we move to discussing the quantities resulting from negotiations and auctions. To do so, we specify the surplus function on the line as $S_{i}\left(q_{i}\right)=\theta_{i}^{S} \log q_{i}$. This functional form ensures that surplus is non-negative and increases in quantity, and the marginal surplus of additional quantity is decreasing. This functional form also allows the marginal benefits of quantity to differ between lines according to $\theta_{i}^{S}$. We assume that $\theta_{i}^{S}=\exp \left(x_{i}^{\prime} \sigma+\epsilon_{i}^{\sigma}\right)$, thus ensuring that the marginal surplus is non-negative and varies across lines according to a parameter vector $\sigma$ that is to be estimated. We also specify a functional form for the bargaining power of the incumbent is $P_{i}=1-\exp \left(x_{i}^{\prime} \pi+\epsilon_{i}^{\pi}\right)$, where $\pi$ is a parameter vector to be estimated. Note that this functional form ensures that the bargaining power of the incumbent is less than 1 but not necessarily larger than zero. Estimates nevertheless indicate average bargaining power to be larger than zero (see below). We adopt this functional form because it leads to a convenient log-linear specification of bargaining power of the incumbent. The central issue in the empirical analysis will be to assess whether the intercept in the bargaining power vector is significantly different from zero. This is a test of whether the incumbent has bargaining power on the average line.

Agencies maximize net surplus taking incumbent power into account. Hence, using (1), the quantity resulting from direct negotiations between the incumbent supplier and the agency is given by

$$
q_{i}^{N}=\frac{\theta_{i}^{S}}{\left(1-P_{i}^{N}\right) t_{i}^{N}}
$$

Inserting the parametrization of $t_{i}^{N}$, we obtain the following characterization of quantity following direct 
negotiations:

$$
\log q_{i}^{N}=x_{i}^{\prime}(\sigma-\pi-\nu)+\epsilon_{i}^{\sigma}-\epsilon_{i}^{\nu}-\epsilon_{i}^{\alpha}
$$

Agencies choose quantities so as to maximize expected net consumer surplus $\theta_{i}^{S} \log q_{i}-t_{i}^{A} q_{i}$. Auctions therefore result in a quantity

$$
q_{i}^{A}=\frac{\theta_{i}^{S}}{t_{i}^{A}}=\frac{\theta_{i}^{S}}{\exp \left(x_{i}^{\prime} \alpha+\epsilon_{i}^{\alpha}\right) t_{i}^{N}}
$$

Again, inserting the parametrization for prices and surplus, we obtain the following specification for log quantities:

$$
\begin{aligned}
\log q_{i}= & x_{i}^{\prime}(\sigma-\pi-\nu)+\epsilon_{i}^{\sigma}-\epsilon_{i}^{\pi}-\epsilon_{i}^{\nu}+ \\
& D_{i}\left(x_{i}^{\prime}(\pi-\alpha)+\epsilon_{i}^{\pi}-\epsilon_{i}^{\alpha}\right)
\end{aligned}
$$

Finally, the first stage choice of procurement mode is straightforward to characterize. The agency will choose the procurement mode that maximizes net consumer surplus taking the incumbent's bargaining power into account. Following (3), an auction is chosen if and only if

$$
\theta_{i}^{S} \log q_{i}^{A}-t_{i}^{A} q_{i}^{A}+P_{i}^{A} t_{i}^{A} q_{i}^{A}-F_{i j} \geqq \theta_{i}^{S} \log q_{i}^{N}-t_{i}^{N} q_{i}^{N}+P_{i}^{N} t_{i}^{N} q_{i}^{N} .
$$

We assume that the incumbent's say in auctions can be captured by $P_{i}^{A}=x_{i}^{\prime} \beta+\epsilon_{i}^{\beta}$. Note that in contrast to the specification for the bargaining power in negotiation, we adopt a simple linear index parametrization. This parametrization does not restrict the bargaining power of the incumbent's say in auctions to be between zero and one. Nevertheless, the linear parametrization offers the key advantage that the procurement choice equation is linear. Moreover, we assume that auction-specific fixed costs are proportional to an agency-specific fixed cost of setting up an auction $F_{j}$ and to the marginal benefit $\theta_{i}^{S}$ of expanding passenger services, i.e. $F_{i j}=\theta_{i}^{S} F_{j}$. This assumption reflects two elements: agencies differ strongly in terms of the ease of handling an auction, and auctioning lines that are served very frequently is more costly than auctioning lines that are served less frequently.

Introducing these parametrization and rearranging, the probability that that line $i$ is auctioned rather than negotiated is

$$
\operatorname{Prob}\left(D_{i}=1 \mid x_{i}\right)=\operatorname{Prob}\left(x_{i}^{\prime}(\pi-\alpha+\beta)-F_{j}+\epsilon_{i}^{\pi}-\epsilon_{i}^{\alpha}+\epsilon_{i}^{\beta} \geqq 0\right) .
$$

This is a standard linear index specification of the probability of choosing an auction over negotiating with the incumbent supplier. Importantly, the same characteristics $x_{i}$ that matter for the frequency of service and for the procurement prices matter in the procurement mode choice equation. In addition to these variables, agency specific fixed effects reflect differences in the fixed costs of setting up an auction. These agency specific effects are absent from the price and quantity equations but they are key to predicting procurement mode. 


\subsection{Identification}

The empirical specification of the structural model contains five sets of parameter vectors: $\nu$ and $\alpha$ that characterize procurement price setting, $\sigma$ and $\pi$ that characterize quantity setting (in addition to the parameters $\nu$ and $\alpha$ ), and $\beta$ that characterizes the incumbent's power in auctions. These parameters can be identified once all reduced form parameters are estimated. Identification proceeds as follows. The price regression identifies $\nu$ and $\alpha$ directly. Thus, we can identify the effects of line characteristics on the procurement price under negotiations as well as on the procurement price reduction resulting from auctions.

Adding the coefficients in the interaction terms in the quantity and price regression $((\pi-\alpha)+\alpha)$ identifies the coefficient vector $\pi$ measuring the relation between line characteristics and power of the agency. Specifically, the sum of the coefficients on the competition dummy in the quantity and price equations $\left(\pi_{0}-\alpha_{0}\right.$ and $\left.\alpha_{0}\right)$ is the average measure of agency power. If it is below 0 , then $1-P_{i}^{N}<1$, that is, the firm has power on an average line.

We get $\sigma$ as $(\sigma-\pi-\nu)+(\pi-\alpha)+\alpha+\nu$, that is, as the sum of all four coefficient vectors. This captures the effects of line characteristics on surplus. Specifically, the sum of the two regression constants and the coefficients on the competition dummies is a measure of the average surplus coefficient.

Finally, the parameter vector $\beta$ is identified from the reduced form parameters in the procurement equation and the knowledge on the parameter vectors $\pi$ and $\alpha$ from the log procurement price equation (4) and the $\log$ quantity equation (5).

\subsection{Endogeneity of procurement choice and Functional Form}

Procurement choice is endogenous if the unobserved determinants of procurement choice $\epsilon_{i}^{P} \equiv \epsilon_{i}^{\alpha}-\epsilon_{i}^{\pi}-\epsilon_{i}^{\beta}$ are correlated with the unobserved determinants of log quantity, $\epsilon_{i}^{\sigma}-\epsilon_{i}^{\pi}-\epsilon_{i}^{\nu}+D_{i}\left(\epsilon_{i}^{\pi}-\epsilon_{i}^{\alpha}\right)$ or $\log$ procurement price $\epsilon_{i}^{\nu}+D_{i} \epsilon_{i}^{\alpha}$. If there is a correlation, equations (5), (6), and (4) need to be estimated jointly.

The empirical model has been well-studied in micro-econometrics. Maddala (1983) calls it a switching regression framework. Cameron and Trivedi (2005) discuss estimation of the switching regression model. They argue that identification requires valid instruments, and that parametric estimates which assume joint normality of the residuals are not robust. Generally, identification and estimation of the full model structure is complex. In particular, separate identification of the distribution of model errors in both the auction and the negotiation regime is challenging. Here, we focus on estimation of the effect of auctions on price and quantity. These parameters can readily be identified using a partial linear approach or a series expansion approach (see Cameron and Trivedi 2005).

Endogeneity of procurement choice implies that mean log quantity needs to be corrected by a term reflecting the conditional mean of unobserved determinants of quantity for lines chosen to be auctioned and a similar term for lines negotiated with the incumbent. A parametric correction inspired by Heckman (1979)'s work on sample selection assumes joint normality of the errors in (5) and (6). This assumption allows estimating a control function involving the so-called inverse Mills ratio (the hazard rate) in two steps. First, 
estimate the selection equation (6) and resulting control function. Second, estimate the quantity equation (5) adding the control function and correct standard errors.

We opt for a more recent semi-parametric approach to dealing with endogeneity along the lines surveyed by Vella (1998). ${ }^{32}$ The semi-parametric approach also has two steps. First, estimate equation (6). We estimate this using the linear probability model. Second, include estimates of $\epsilon_{i}^{A}$ in the quantity equation (5). The key difference between the two approaches is in the control function. Rather than plugging in a control function provided by joint normality, the semi-parametric approach approximates the unknown control function by a flexible approximation. We provide results using just the estimated residuals to approximate the control function. Inference is based on the bootstrap with 1000 replications. Specifically, we bootstrap the entire two step procedure (accounting for clustering at the agency level) and report bootstrap standard errors.

Identification of endogenous switching models requires instruments. The theoretical model provides a rationale for using agency dummies as instruments. We assume that agencies vary with respect to their preferences concerning auctions, which is captured through the agency-parameter $F_{j}$. In contrast, quantity is determined by surplus, firm power and prices, not by agency-specific parameters. This leaves little room for agencies in setting quantity. A key concern with this identification strategy is that there are potential differences in line specific unobserved and time-invariant characteristics. We discuss the relevance of these characteristics by analyzing the quantity of service supplied prior to the reform. We find that pre-reform quantity is unrelated to procurement mode once a line's remoteness, length, and demand proxies have been taken into account. We are therefore confident that line specific unobserved but constant characteristics are not driving results.

Even if endogeneity of procurement choice is not an issue, assumptions concerning the functional form of the estimating equation (5) can bias results. To assess whether functional form is an issue, we apply nearest-neighbor matching proposed by Abadie and Imbens (2002) and implemented by Abadie et al. (2004). Intuitively, we match a line that was auctioned with the line that is most similar in terms of observed characteristics but that was not auctioned. Formally, suppose line $i$ with covariate vector $x_{i}$ is auctioned. Nearest neighbor matching selects the line $j$ with covariates $x_{j}$ such that $j$ is not auctioned and has smallest Mahalanobis distance $d(i, j) \equiv \sqrt{\left(x_{i}-x_{j}\right) \Sigma^{-1}\left(x_{i}-x_{j}\right)}$ (with $\Sigma$ denoting the variance-covariance matrix of the characteristics $x_{i}$ ). The effect of procurement mode on quantity or on price is then estimated comparing the line that was auctioned to the nearest neighbor in terms of Mahalanobis distance. We provide results that use an additional regression step to correct for bias due to inexact matches. Again, we account for clustering at the agency level by performing a clustered bootstrap procedure (with 100 replications only due to the time consuming nature of the nearest neighbor matching algorithm).

\footnotetext{
${ }^{32}$ See also Fan and $\mathrm{Wu}(2010)$ for a recent discussion of bounding the distribution of treatment effects. We are concerned with estimating average treatment effects.
} 


\section{Data}

The empirical analysis uses information on service quantity and procurement prices. We first require a measure of the service quantity on a line. We use the frequency of service, the ratio between train kilometers per year $(\mathrm{tkm})$ and the length of a line $(\mathrm{km}) .{ }^{33}$ We chose its value in the year 2004 on a particular line as the quantity to be explained, but we also included a lagged frequency of service (for 1994) as a control variable. The division of the network into different lines follows the 2004 timetable. $^{34}$

We do not have data that measure aspects of service quality such as punctuality, comfort, etc. However, while we believe it would be interesting in itself to see how these variables are affected by competition, we do not expect competition to affect quality strongly. For one thing, many aspects of quality are narrowly specified in most contracts. For another, to the extent that there is flexibility in the choice of quality, anecdotal evidence does not suggest there is lower quality on the competitive lines.

To identify competition effects, we classified lines as competitive if at least $20 \%$ of the services were procured competitively. ${ }^{35}$ Clearly, the fact that a line is served competitively says nothing about ownership: If $D B$ Regio has won a line in a competitive tender, then the line is defined as competitive even though the owner is the incumbent. Conversely, but much less importantly, a few small lines are served by other companies, but have been procured by direct negotiations. We discuss the role of ownership and auctions in a separate analysis below. ${ }^{36}$

Apart from these basic variables, we added further controls, corresponding to the line characteristics discussed in Section 4. These characteristics are mostly determined by geography. We consider the geographic distance to the nearest city with at least 100,000 inhabitants as a measure of remoteness. We also include the number of inhabitants of both the largest and the second-biggest city served by the line in 1994 . We do not condition on the number of inhabitants in 2004 since frequency of service may affect population growth along a line. We discuss the role of auctions in affecting population below. Finally, we include dummies for the agency that procures the railway services.

Obtaining information on the procurement prices is difficult. We were able to get information on procurement prices of the winning bid in auctions from a firm that is specialized in consulting on regional passenger train service (Nahverkehrsberatung Südwest, Heidelberg, Felix Berschin). This data contains information on prices for 63 of the 138 competitively procured lines in the sample. We have studied whether these lines represent a selected sample but, conditional on the observed line characteristics, we did not find any differences

\footnotetext{
${ }^{33}$ Thus, the frequency of service corresponds to the average number of trains per year on each kilometer of tracks.

${ }^{34}$ Some adjustments were necessary, however, to avoid double-counting of trains. Lines that were closed down between 1994 and 2004 were not included.

${ }^{35}$ We also included lines of the following - comparatively rare - types: (i) Services were procured on the basis of offers from at least two firms that were approached directly by the agency; (ii) Apart from the incumbent, at least one firm offered a contract to the agency without having been asked to do so. (iii) A competitor took over the infrastructure and the task of running services from $D B$ Regio for a symbolic price (see Lalive and Schmutzler (2008) for examples).

${ }^{36}$ In analogy to our definition of competitive lines, we define a line as operated by DB Regio if at most $20 \%$ of the services were run by competitors.
} 
between the lines with price data and lines without price data. ${ }^{37}$

The prices resulting from direct negotiations are publicly available but only quoted at the state level. We construct individual line specific estimates of the negotiation price as follows. As usual in network industries, the downstream firms have to pay access fees to the network owner, which almost always is DB Netz. These access fees, which constitute a substantial part of the costs of downstream firms, vary considerably across lines. We reconstruct negotiation prices to reflect the access fee along with a region specific cost component so as to match the quoted state level price (see the Appendix for details). ${ }^{38}$

\section{Econometric Results}

We now present our main observations about frequency of service and procurement prices on lines that were negotiated and on lines that were auctioned. In the following, we compare auctions and direct negotiations in an econometric analysis based on the model of Section 4. Note that even though the empirical specifications are motivated by the theoretical model, Sections 7.1 to 7.5 present only reduced form effects. These are valid even if the theoretical framework is not.

\subsection{Descriptive Statistics}

Figure 1 displays kernel density estimates of the distribution of frequency of service in 2004 for two sets of lines: lines that were auctioned between 1994 and 2004 as opposed to lines that were negotiated directly with the incumbent supplier. The main difference is that the auctioned group contains relatively fewer lines with very high frequency of service and more lines with medium frequency of service. In itself, this observation does not lend itself to a clear interpretation. It could reflect a pure selection effect or a causal effect that competition stifles growth.

insert Figure 1 here

Figure 2 is more informative about the source of the differences. Rather than depicting the density of the frequency of service on auctioned vs. negotiated lines, it compares their changes. This picture is revealing. It shows that the auctioned lines have typically grown much stronger than the negotiated lines. This strongly suggests that Figure 1 should not be given a causal interpretation: The difference between the auctioned and the negotiated lines was much larger in 1994 than in in 2004. It appears that competition has helped to close the gap between the auctioned and the negotiated lines. Of course, Figure 2 is not fully conclusive about a causal relation either. It shows that the auctioned lines have grown stronger than the others, but again this may reflect a selection effect. The auctioned lines may have been systematically different from their

\footnotetext{
${ }^{37}$ We have also explored another source of data on prices. The official source of the European Union, the databank Tender Electronic Daily, contains useful information on which lines were grouped together in a particular auction and what the overall volume of the contract is. Procurement price data are only available in some cases.

${ }^{38}$ We are grateful to DB Netz for providing us with information on the access charges.
} 
negotiated counterparts, and their growth may reflect these systematic differences rather than any actual merits of competition. In the following, we try to substantiate the claim that there is indeed a causal relation between competition and service quality.

insert Figure 2 here

\subsection{Selection of Auctioned Lines}

We first ask whether auctioned lines are systematically different from the lines in the control group. Table 1 provides an empirical description of lines auctioned between 1994 and 2004, and lines procured in direct negotiation with the incumbent in 2004. A total of 138 lines or about $25 \%$ of the total of 551 lines were auctioned. Lines procured by auctions were less frequently served than lines procured in direct negotiations. In 2004, the frequency of service is about 8 percent lower on lines auctioned than on lines negotiated. Yet, this is a huge improvement compared to 1994 when the auctioned lines were 20 percent less frequently served than the negotiated lines. Auctions are typically associated with a change in ownership. Whereas $93 \%$ of all lines that were directly negotiated with the incumbent are served by it, only $20 \%$ of all lines which were auctioned are operated by the incumbent. We explore further below whether the effects of auctions resulting in a change in ownership differed from the auctions where the incumbent won. The table also discusses the type of contract. Whereas $67 \%$ of all the contracts resulting from auctions are net contracts, $93 \%$ of all lines that are directly negotiated are procured using net contracts.

insert Table 1 about here

Table 1 also shows that auctioned lines are less likely to be equipped with electric traction (24 percentage points), more remote ( $8 \mathrm{~km}$ farther from city), serve cities that were less populated in 1994 (largest city 47 percent smaller; second largest city 34 percent smaller) than lines that were negotiated.

Table 2 investigates the determinants of frequency of service in 1994. The central idea of this analysis is to assess whether the line characteristics predict the frequency of service. The first column shows that the frequency of service is approximately $20 \%$ lower on lines that were auctioned rather than negotiated with the incumbent. This analysis therefore repeats the pure descriptive result that lines to be auctioned between 1994 and 2004 are not as frequently served in 1994 as lines that were directly negotiated. After controlling for characteristics reflecting surplus and cost, however, lines to be auctioned do not differ from lines to be negotiated with the incumbent. This is an important result. It states that, conditional on observed characteristics of lines, there are no unobserved characteristics of lines pertaining to quantity that are systematically related to procurement status. This result also implies that estimates of the effect of auctions on service quality cannot be biased due to time invariant unobserved characteristics. ${ }^{39}$

\footnotetext{
${ }^{39}$ We can support this claim by studying frequency of service in 1994. If there are time invariant unobserved characteristics that are correlated with procurement mode, we detect them in the analysis of pre-reform quantity. Since we do not find any unexplained association, we are confident that once the characteristics of lines are included, the resulting procurement effect is not driven by time invariant unobserved characteristics.
} 
There are three additional important factors predicting frequency of service. First, the frequency of service was much higher on lines that were electrified compared to lines with diesel traction or other traction. Second, remoteness plays a small but significant role: The frequency of service on a line that is 100 kilometers from a big city is about $4 \%$ lower than on a line that serves a big city. Similarly, the population of the second-largest city plays a role: When the second-largest town is 10\% larger, the frequency of service is approximately $1 \%$ higher.

Table 3 shows the results of a linear probability analysis of the choice of procurement mode (equation 6$){ }^{40}$ Column "base" provides a baseline analysis that explains procurement choice with frequency of service in 1994. Results clearly suggest that auctioned lines were less frequently served before the railway reform. Column "controls" adds background information on the lines and the markets that are served. We control only for time-invariant characteristics and population in 1994 because contemporaneous time-varying characteristics are endogenous. Results now indicate that the frequency of service in 1994 no longer predicts procurement mode in 2004. This result testifies to the quality of the available line characteristics, and it means that there are no time-invariant unobserved characteristics of lines that are correlated with frequency of service and determine procurement choice. Which characteristics matter for procurement choice? Lines with electric traction are 17 percentage points less likely to be auctioned. In the context of our theoretical framework, this reflects that the expected cost reductions from auctions on these lines are low. Similarly, lines serving cities that are highly populated are less likely to be auctioned (the parameter is not significant at the $10 \%$ level but close to it). Column "agency" adds agency-specific fixed effects. ${ }^{41}$ These are not reported directly in the table, but it is clear that they matter. The F-statistic indicates that they are significant with a P-Value of less than $1 \%$.

Tables 2 and 3 are encouraging. Even though there are systematic differences between auctioned and non-auctioned lines, results in tables 2 and 3 suggest we understand the sources of these differences. This increases our confidence in the validity of our econometric approach to determining the effects of competition on service quality in 2004 .

\subsection{Auction Effects on Quantity}

Table 4 presents estimates of the effect of auctions compared to negotiations on frequency of service using an OLS-regression. The column "base" controls only for observed characteristics and lagged frequency of service. Results indicate that auctioned lines are 14 percent $\{=[\exp (.132)-1] * 100\}$ more frequently served than lines procured in direct negotiations with the incumbent. Lines that were served frequently in 1994 also

\footnotetext{
${ }^{40}$ Moffitt (1999) argues that linear probability models are more convenient and often just as accurate as probit and logit. We use linear probability also because some agencies do not auction any lines. Probit - assuming that the probability of seeing a line auctioned is never exactly zero - automatically discards lines procured by these agencies. We believe that this is not justified since agencies may very well end up never procuring lines for reasons modeled within our framework. Results are, however, not sensitive to discarding lines procured by agencies who never opt for auction.

${ }^{41}$ In terms of the model, these effects reflect the heterogeneity of agencies with respect to the cost of carrying out auctions.
} 
are more frequently served in 2004. Note that we include lagged frequency of service to correct for timeinvariant unobserved effects in our analysis, so that the coefficient attached to lagged frequency of service has no causal interpretation. Results also indicate that lines with electric traction are served about 6 percent more frequently than lines with diesel traction. Longer lines are less frequently served than shorter lines. The remaining control variables are not significant mainly due to the fact that we condition on lagged frequency of service. ${ }^{42}$

insert Table 4 here

Column "interactions" presents estimates of equation (5). The essential difference to the column "base" is that now all line characteristics are interacted with the auction dummy. Note that before forming interactions, we subtract the mean of the variable. This ensures that the main effect of being auctioned reflects the mean effect of being auctioned for the average line in the sample. ${ }^{43}$ Results indicate the average effect of procurement by auction is $16 \%$, or slightly higher than in specification "base". The interaction specification also finds significant differences in the effects of auctions on quantity. The interaction effect on population in the largest city is positive, suggesting that lines serving large centers benefit more strongly from being auctioned than lines serving less populated centers. In contrast, the negative interaction term on frequency of service in 1994 suggests that auction-related quantity improvements are smaller on lines that were served very frequently already before the reform. The model with interactions statistically dominates the basic model that does not allow for interaction terms.

Column "joint" provides estimates of equation (5) that correct for endogeneity of procurement choice in a semi-parametric fashion (see Section "Endogeneity of Procurement Choice"). This model enters the unexplained component of the procurement choice equation into the quantity equation. The parameter attached to the procurement choice residual is key in discussing endogeneity of procurement choice. If residuals enter the quantity equation significantly, then procurement choice depends on unobserved determinants of procurement choice. Results indicate that procurement choice residuals do not enter significantly. This means that agencies chose lines to be auctioned based on the variables that we observe (traction, population) rather than on unobserved line characteristics. Estimates also indicate that the coefficient on the interaction term of the auction dummy and the procurement residual is not significantly different from zero. ${ }^{44}$ This means

\footnotetext{
${ }^{42} \mathrm{~A}$ regression that does not include lagged frequency of service finds all observed characteristics matter for frequency of service in 2004. That regression finds point estimate suggesting an $11 \%$ auction effect, albeit much less precisely estimated (since the standard error of regression is larger).

${ }^{43}$ The regression we run is of the form $y_{i}=\left(x_{i}-\bar{x}\right)^{\prime} \beta+D_{i} \times\left(x_{i}-\bar{x}\right)^{\prime} \delta+\epsilon_{i}$ where $\bar{x}$ is the sample average of the observed characteristics, and $D_{i}$ is 1 if line $i$ is auctioned, and $D_{i}$ is zero otherwise. Note that $x_{i}$ contains an intercept and we do not demean the intercept. The coefficient $\delta_{0}$ attached to the interaction term between $D_{i}$ and the intercept measures the effect of being auctioned on the average line.

${ }^{44}$ We have explored two important alternative approaches. First, we have also added higher order polynomials of the procurement choice residuals but we do not find that they matter. Second, we have also estimated a parametric endogenous regime switching model that assumes joint normality of residuals. This model also finds endogeneity is not an issue. Results are available upon request from the authors.
} 
that there are no unobserved characteristics of lines that generate larger or smaller cost reductions due to auctions. The auction effect loses significance because auction procurement is strongly correlated with the residual from the auction equation. The interaction effects between auction status and population and prior service remain significant and quantitatively at similar levels. Yet since endogeneity is not a concern, the "interaction" model is preferred to the "joint" model.

A potentially important concern with the "interactions" model is the choice of functional form. Column "match" reports exact nearest neighbor matching estimates of the average effects of procurement by auction on frequency of service as a sensitivity analysis (sample average treatment effect). Results indicate that the average line in the sample benefits from an 18 percent increase in frequency of service when procurement involves auctions rather than direct negotiations with the incumbent. This effect is slightly but not significantly higher than the least squares results in column "interactions". We are therefore confident that the preferred "interaction" estimates are not driven by functional form assumptions.

\subsection{Auction Effects on Procurement Prices}

The preceding analysis has identified a positive effect of competition on the frequency of service. We have argued that this is likely to reflect the fact that agencies who are facing competitive bidders understand that they can ask for more than from a monopolistic supplier, because any unit of service costs less. So far, however, we have not produced any evidence to corroborate this story. ${ }^{45}$ In principle, there could be completely different explanations for the stronger growth on auctioned lines. For instance, agencies that are experimenting with auctions might be afraid about failure of the project. As the public is more likely to be aware of low quality rather than excessively high procurement costs, agencies might want to make sure that competitively procured lines "look better" than others by pumping more money into them. In other words, the high quantity of services on competitively procured lines might simply reflect higher payments.

Table 5 therefore discusses the effect of auctions on procurement prices. ${ }^{46}$ Results follow the same structure as the quantity results (Table 4). Column "base" indicates that the price on auctioned lines is 22 percent $\{=[\exp (-.253)-1] * 100\}$ lower than on lines that are procured using direct negotiations between the agency and the incumbent. This suggests that auctions not only increase quantity but they also lower the procurement price. In addition to the procurement mode, two additional characteristics are correlated with procurement prices. Remote lines and lines that are served very frequently have a lower procurement price (significant at the $15 \%$ level only). Note that the analysis corrects for differences in contract type with the dummy variable "net contract". Net contracts do not turn out to have different procurement prices than gross contracts. Neither do the other characteristics predict procurement prices.

\footnotetext{
${ }^{45}$ This problem is shared by the analysis in Lalive and Schmutzler (2008) for Baden-Württemberg.

${ }^{46}$ This analysis is based on 476 lines with procurement price information. We construct negotiation prices for all 413 lines that were directly negotiated with the incumbent (see Appendix). We also have information on auction prices for 63 lines that were auctioned.
} 
insert Table 5 about here

Column "interactions" asks whether the procurement price reduction is related to line characteristics. Results indicate that the average line benefits from a 25 percent reduction in the procurement price when auctioned compared to direct negotiations. This estimate is slightly but not significantly larger than the estimate in the "base" column. Furthermore, auctions lead to a further 15 percent reduction in procurement prices on lines with electric traction. In contrast, the price reduction potential is smaller on lines that were frequently served in 1994 (the interaction term auction * log frequency of service is statistically significant at the $15 \%$ level). None of the remaining interaction terms are statistically significantly different from zero. Nevertheless, the "interactions" model is statistically preferred to the base model (F-test on interaction terms rejects the null hypothesis).

We further test for endogeneity of the price equation with respect to procurement mode. Column "joint" estimates the price-setting equation jointly with the procurement choice equation. The coefficient on the procurement choice residual is not statistically significantly different from zero. Interestingly, the interaction term of auctioned lines with the procurement choice residual is negative and quite important. This suggests lines that were particularly likely to be auctioned also needed to be subsidized less. The coefficient on the auction status of the line is not statistically significantly different from zero but preserves the economic magnitude. This can be explained, again, by strong correlation between the procurement status of the line and the procurement residual. But note since procurement choice is not endogenous, the results in column "interactions" are preferred to the results in column "joint".

As a sensitivity analysis, column "match" reports nearest neighbor matching results. These results also indicate that lines that were auctioned were served at lower procurement price than lines that were negotiated. Interestingly, the magnitude of the effect is very similar to the one reported in column "interactions" that was estimated by least squares. Results are not sensitive to functional form.

Overall, these results suggest that the procurement price is on the order of 26 percent lower on lines that were auctioned compared to similar lines that were directly negotiated, suggesting that markups and/or costs were substantially lower on the competitively procured lines. We can interpret the 26 percent as an upper bound to the markup effect, with the difference to the actual markup effect reflecting the cost advantages of auctions. Moreover, the fact that auctions lead to lower procurement prices clearly indicates that quantity improvements were efficiency enhancing.

\subsection{Explaining Auction Effects}

The preceding results suggest that auctions lead to higher frequency of service and lower procurement prices. Auctions appear to be an efficiency enhancing procurement mode. However, one might argue that agencies selected lines to be auctioned that were expected to face higher demand. This would change the interpretation of the positive quantity effects of auctions. If auctioned lines expand merely to accommodate stronger demand, the resulting quantity effect may not result from the procurement mode as such. If procurement mode were 
affected by demand expectations, we could not rule out reverse causality in the estimated effects of auction on quantity.

Table 6 reports the effects of auctions on two important demand indicators: the (log) population in the largest city along the line (column "pop1", and the (log) population in the second largest city along the line (column "pop2"). Results indicate that the procurement status of a line is not significantly related to the number of inhabitants in the largest or second largest city along the line. This result suggests that improvements in the frequency of service were not driven by demand.

insert Table 6 about here

Why do auctions improve quantity and reduce price? There are two competing hypotheses, corresponding to the sampling and rent-reducing effects discussed in Section 2. On one hand, auctions often lead to a change in the identity of the firm providing the service. New entrants might be able to provide the same level of service at lower cost. On the other hand, auctions introduce competitive pressure leading to lower procurement prices and higher quantity also for the incumbent firm. We can discuss these competing explanations by assessing the role of auctions and ownership.

Column "incumbent" reports the effect of auctions on change in ownership. Results indicate that the incumbent supplier is 71 percentage points less likely to serve a line that is auctioned than a line that is directly negotiated. These results confirm that auctions imply a significant transfer of ownership rights. Column "quantity" discusses the role of auctions and ownership in setting quantity by introducing an interaction term "auction * incumbent" along the main effect of auction. Results indicate that auctions lead to a 15 percent increase in frequency of service provided the incumbent does not win the auction. This effect is very much in line with the estimate of our preferred model for quantity. Interestingly, the effect of an auction on the frequency of service is slightly but insignificantly less important on lines that are operated by the incumbent supplier. Column "price" discusses the role of auctions and ownership for price. Results indicate that auctions reduce procurement prices by 23 percent on lines that are served by an entrant. The price reduction is very much the same for lines that are auctioned by operated by the incumbent. Taken together, these results suggest that the quantity improvements and price reductions of procurement auctions are explained by competition rather than ownership changes.

\subsection{Discussion of Structural Parameter Estimates}

We now move to the interpretation of results that depend on the details of the theoretical framework. Table 7 presents the estimates of all structural parameters of the model. By definition, the parameter vectors $\nu$ and $\alpha$ coincide with the coefficients of the price regression, so that we refrain from discussing them any further.

insert Table 7 about here

First, consider the vector $\pi$. From the parametrization $\left(1-P_{i}^{N}\right)=\exp \left(x_{i}^{\prime} \pi+\epsilon_{i}^{\pi}\right)$, a value of $\pi_{0}=0$ corresponds to the absence of power of the incumbent in the negotiation; a negative value corresponds to the 
existence of power. Table 7 shows that $\pi_{0}=-0.153<0$, and the coefficient is significantly different from zero. Because the power index is the product of the markup and the incumbent weight in the negotiations, the result suggests that the firm expects a positive markup and uses its weight in the negotiation to expand the quantity beyond what the agency finds optimal. Moreover, the results suggest that incumbent bargaining power acts as tough the transfer price were reduced by $14 \%$ for the average line $(=(\exp (-.153)-1) \times 100)$. The remaining line characteristics have no influence, at least not individually.

Next, consider $\beta$, which corresponds to the power of the firm in auctions via $P_{i}^{A}=x_{i}^{\prime} \beta+\epsilon_{i}^{\beta}$. From the definition $P_{i}^{A} \equiv \tau_{i} r_{i} M_{i}^{A}$, this power index reflects both which profits the incumbent expects in an auction and to which extent its preferences are accounted for in the negotiations on the procurement mode. Specifically, a parameter value of $\beta_{0}>0$ will arise if the incumbent has a voice in the negotiations on the procurement mode and expects to obtain some positive profits even in an auction. The (insignificant) estimate $\beta_{0}=0.102$ suggests that this is indeed correct. It is interesting to compare the power of the firm under auctions and negotiations. As $\frac{P_{i}^{A}}{P_{i}^{N}}=\frac{r_{i} M_{i}^{A}}{M_{i}^{N}}$, the ratio of the two indices should be smaller than one if the incumbent expects its markup to be smaller under auctions than under negotiations and also expects that it will not win with probability one. Using $P_{i}^{N}=1-\exp \left(\pi_{0}\right)=0.141$ and $P_{i}^{A}=\beta_{0}=0.102$, we obtain an estimate $\frac{r_{i} M_{i}^{A}}{M_{i}^{N}}=0.723$. While this index is smaller than one, it is somewhat higher than one would expect if (i) the incumbent correctly anticipates the probability of winning the auction and (ii) the margins under auctions are indeed lower than under negotiations. ${ }^{47}$

Three points about the coefficients of the vector $\sigma$ are worth mentioning. First, using the estimate for $\sigma_{0}$, one obtains a specification of the agency surplus for an average line as $\exp (11.56) \log q_{i}$. Second, the positive and significant coefficient on log frequency of service in 1994 suggests that the marginal surplus of expanding the frequency of service on lines that were already served well in 1994 is larger than on lines that were not served frequently in 1994. Third, the marginal surplus of expanding the frequency of service is lower on long tracks than on short tracks.

What are the effects of using auctions vs. negotiations to procure regional passenger rail services? Table 8 presents the effects of auctions on prices, quantities, and net surplus and its components. The table contrasts three situations. Column A assumes all lines are procured using negotiations. Column B assumes all lines are procured using auctions, and column $\mathrm{C}$ assumes all lines are procured using negotiations but setting bargaining power of the incumbent to zero. Results indicate that auctions increase quantity by 16 percent and reduce the transfer price by 25 percent compared to negotiations (column A vs B; top two rows). Auctions lower the transfer payments of providing regional passenger service by 70 Euros, from 397 Euros to 327 Euros, per calender day and line kilometer - a 17.5 percent reduction in transfer payments (row three). Yet auctions reduce transfer payments and they increase surplus. The effects on transfer payments represent merely a lower bound of the effects on net agency surplus. What is the overall effect of choosing auctions

\footnotetext{
${ }^{47}$ At least for the time under consideration, the incumbent won less than half of the auctions. But note that the ratio of the two power estimates is not significantly different from zero. This means that the data is consistent with no incumbent power at all in first stage negotiations on auctions vs negotiations.
} 
compared to negotiations in public procurement? Reduced form estimates alone do not allow answering this question. We use our estimates of the line surplus function to assess the surplus effects of auctions. Estimates indicate that surplus increases by 46 Euros, from 3231 Euros to 3277 Euros, per line kilometer and calendar day (row four). This change is small when compared to average surplus (1.4 percent) but quite substantial when compared to average transfer payments (11.5 percent). Taken together, we find that auctions increase net agency surplus by 115 Euros, from 2834 Euros to 2949 Euros, per line kilometer and calendar day (4 percent of net surplus; row five). Is this a large or a small effect? An intuitively appealing statistic is the change in net agency surplus due to auctions relative to the average transfer payments with negotiations. This figure provides an estimate of the change in net agency surplus per Euro procured by auction rather than negotiation. ${ }^{48}$ We find that the increase of net agency surplus due to using auctions rather than negotiations amounts to $29 \%$ of the transfer payments the agency would have had to pay with negotiations (=115 Euros relative to 397 Euros; figure in curly brackets in row 5). We conclude that auctions are indeed very important in enhancing net agency surplus.

insert Table 8 about here

There are two problems associated with negotiations. Negotiations involve higher procurement prices and the incumbent's influence leads to a higher than optimal quantity in the negotiations. Auctions undo both problems but which of the two effects contributes to increasing net surplus more strongly? Column $\mathrm{C}$ in Table 8 displays outcomes that assume bargaining power of the incumbent is zero (set $P_{i}=0$ in equation 1). Results indicate that eliminating the incumbent's bargaining power increases net surplus only slightly, from 2834 to 2843 ( 0.3 percent of net surplus or 2.3 percent of transfer payments; row five, column A vs column C). Auctions enhance efficiency due to the reduction in the transfer price rather than because they eliminate bargaining power. Elimination of bargaining power is ineffective because it reduces the frequency of service while keeping the transfer price constant. Reduced frequency of service decreases transfer payments and surplus. The change in net agency surplus is positive but close to zero.

We also calculate net surplus effects separately by whether a line was auctioned or not. Results indicate that the rate of return on public subsidies is 24 percent on lines that were auctioned but 30 percent on lines that were not auctioned (results are not shown). This indicates that agencies did not focus on auctioning the lines that would have benefited most strongly from being auctioned. Figure 3 discusses why the net surplus gains from using auctions is larger for lines that were negotiated compared to lines that were auctioned. It plots the net surplus gain for the agency from using an auction rather than a negotiation against the $(\log )$ frequency of service in 1994. The figure suggests that the net surplus gains on the lines with high frequency of service are considerably larger than the net surplus gains on lines that were not served frequently in 1994. The average net surplus gain is smaller for auctioned lines (squares) than for lines that were negotiated with

\footnotetext{
${ }^{48}$ The figure is appealing since it relates changes in net agency surplus to the level of transfer payments rather than the level of net agency surplus. The level of surplus is arguably quite dependent on the assumptions regarding functional form of the surplus function. In contrast, transfer payments are directly observable.
} 
the incumbent (dots) since agencies auctioned lines that were not frequently served in 1994.

insert Figure 3 about here

\section{Summary and Discussion}

Our analysis has shown that competitive procurement has led to lower prices and greater frequency of railway services in Germany. This finding is important. It suggests that the forces of competition can lead to an efficiency improving outcome in regional train services provision.

The result also stands in contrast to the dominant view in theory and some recent experience with auctions in other sectors. Concerning theory, it is unlikely that these particular auctions nicely fit the independentprivate-value paradigm, so that this result was not obvious ex ante. So what are the circumstances that were responsible for this outcome?

Some of the standard concerns against auctions are likely to be of limited importance in the case at hand. First, the services that are procured do not appear to be overwhelmingly complex - it seems possible to specify them in a sufficiently precise manner to avoid frequent renegotiation. Second, even when there is need for renegotiation, some attempts have been made to approach it in a sufficiently mechanical way that the functioning of auction mechanisms is not endangered (see Section 3.4). Third, the period under consideration was sufficiently dynamic that collusion was hard to sustain; the speed at which new firms entered the market was very high.

Moreover, the dominant alternative to competitive procurement was arguably particularly unattractive in the specific case. There were huge asymmetries between the agencies and $D B$ Regio, which put the latter in a strong position in the direct negotiations. The former state monopolist still is one of the largest employers in Germany. It faces many small agencies which hardly cooperate. In this setting, it appears quite possible that, in the negotiations the incumbent felt sufficiently powerful to ask for much higher prices than would have resulted with competition for the market. 


\section{$9 \quad$ References}

Abadie, A., and Imbens, G.W. (2002), "Simple and Bias-Corrected Matching Estimators for Average Treatment Effects", NBER Technical Working Papers.

Abadie, A., Drukker, D., Leber Herr, J. and Imbens, G.W. (2004), "Implementing matching estimators for average treatment effects in Stata", The Stata Journal, 4(3): 290-311.

Bajari, P., Houghton, S., und S. Tadelis (2009): "Auctions vs. Negotiations in Procurement: An Empirical Analysis," Journal of Law, Economics, and Organization 25, 372-399.

Bajari, P., und S. Tadelis (2001): "Incentives versus Transaction Costs: A Theory of Procurement Contracts," RAND Journal of Economics,32(3), 387-407.

Banerjee, A.V., and Duflo, E. (2000): "Reputation Effects and the Limits of Contracting," Quarterly Journal of Economics, 115, 989-1017.

Besley, T., and Case, A. (2006), "Unnatural Experiments? Estimating the Effects of Endogenous Policies", Economic Journal 110, F672-694.

Boitani, A., and Cambini, C. (2006), "To Bid or not to Bid, this is the Question: the Italian Experience in Competitive Tendering for Bus Services ", European Transport no. 33, 41-53.

Borrmann, M. (2003), "Ausschreibungen im Schienenpersonennahverkehr", Vandenhoeck und Ruprecht, Göttingen.

Branco, F. (1997), "The Design of Multidimensional Auctions", RAND Journal of Economics 28, 63-81.

Brenck, A., and Peter, B. (2007) "Experience with Competitive Tendering in Germany", in in: ECMT (Ed.): Competitive Tendering of Rail Services, Paris: Chapitre 5, S. 139-164.

Bulow, J., and Klemperer, P. (1996), "Auctions versus Negotiations?", American Economic Review 86, 180194.

Bulow, J., and Klemperer, P. (2002), "Prices and the Winner's Curse", Rand Journal of Economics 33,1-21.

Cameron, A. Colin and Trivedi, Pravin K. (2005), Microeconometrics: Methods And Applications, Cambridge University Press, New York

Cantos, S., Pastor, J.M., and Serrano, L. (2000), "Efficiency measures and output specification: the case of European railways," Journal of Transportation and Statistics 3, 61-68.

Che, Y.-K. (1993), Design Competition through Multidimensional Auctions, RAND Journal of Economics $24,668-680$.

Chong, E., Staropoli, C., and Yvrande-Billon, A. (forthcoming), Auction vs. Negotiation : looking for New Empirical Evidences" In E. Brousseau et J-M. Glachant, Manufacturing Markets, Cambridge University Press.

Cowie, J. (2002), Subsidy and Productivity in the Privatized British Rail Industry, Economic Issues 7, 25-37.

Demsetz, H. (1968): "Why Regulate Utilities?", Journal of Law and Economics 11, 55-65.

Duso, T., and Röller, L.H. (1997), "Endogenous deregulation: evidence from OECD countries", Economics Letters $81,67-71$. 
Fan, Y. and Wu, J. (2010): "Partial Identification of the Distribution of Treatment Effects in Switching Regime Models and its Confidence Sets, ” Review of Economic Studies , 77(3): 1002- 1041.

Friebel, G., Ivaldi, M. and Vibes, C. (2010), "Railway (DE)regulation: A European Efficiency Comparison", Economica 77 (305), 77-91.

Gagnepain, P., Ivaldi, M. and Martimort, D. (2010), "The Cost of Contract Renegotiation: Evidence from the Local Public Sector", mimeo.

Gagnepain, P., and Ivaldi, M. (2010), "Contract Choice, Incentives, and Political Capture in the Private Sector", Unpublished Manuscript.

Goldberg, V. (1977), "Regulation and Administered Contracts", The Bell Journal of Economics 7, 426-448.

Grossman, G. M., Helpman, E. (1996). "Foreign Investment with Endogenous Protection", in: R. C. Feenstra, G. M. Grossman and D. A. Irwin (eds.), The Political Economiy of Trade Policy, MIT PRess, Cambridge, MA

Heckman, J. (1979) Sample selection bias as a specification error. Econometrica, 47, 153-61.

Hensher, D.A., and Wallis, I.P. (2005) "Performance-based Quality Contracts for the Bus Sector: Delivering Social and Commercial Value for Money", Journal of Transportation Economics and Policy 39, 295-322.

Hong, H., und M. Shum (2002): "Increasing Competition and the Winner`s Curse: Evidence from Procurement," Review of Economic Studies, 69, 871-898.

Krozner, R. S., and Strahan, P. (1999) "What drives deregulation? Economics and politics of the relaxation of bank branching restrictions", Quarterly Journal of Economics 114, 1437-1467.

Lalive, R., Luechinger, S., and Schmutzler, A. (2011), "Supporting Passenger Railways to Reduce Externalities", Mimeo, (2011)

Lalive, R., and Schmutzler, A., "Exploring the Effects of Competition for Railway Markets", International Journal of Industrial Organisation, 26, 443-458 (2008).

LNVG (2010), "2013+ - Konzept zum Schienenpersonennahverkehr", Hannover.

Maddala, G. S. (1983), Limited-Dependent and Qualitative Variables in Economics, New York: Cambridge University Press, pp. 257-91

Manelli, A., and Vincent, D. (1995), "Optimal Procurement Mechanisms", Econometrica 63, 591-620.

Mc Afee, R.P., and Mac Millan (1992), "Bidding Rings", American Economic Review 82, 579-599.

Moffitt, Robert A., (1999). "New developments in econometric methods for labor market analysis," Handbook of Labor Economics, in: O. Ashenfelter and D. Card (eds)

Pollitt, M. and Smith, A.S.J. (2001) "The restructuring and privatisation of British Rail: was it really that bad?" Applied Economics Department, Cambridge University, Working Paper No.2001/18

Vella, F. (1998), Estimating Models with Sample Selection Bias: A Survey, The Journal of Human Resources, Vol. 33, No. 1, pp. 127-169

Viscusi, K., Vernon, J. and Harrington, J.E. (2000): Economics of Regulation and Antitrust. MIT-Press, 
Cambridge/MA.

White, P.R. (2000), "Bus Tendering in London - A Critique", Transport for London Workshop, September $29,2000$.

Wilson, R. (1992): "Strategic Analysis of Auctions", in Aumann, R., and Hart, S. (eds.), Handbook of Game Theory, 227-279, North-Holland. 


\section{Appendix: Procurement prices under negotiations}

We show how to construct line-specific prices from the average price in the agency and from information on line-specific access charges. We make the following assumptions. For each individual line $i=1, \ldots, I$, the price charged by DB Regio is calculated using the expected costs of delivering the service. These consist of two parts: The costs of using infrastructure and the costs of running the service (a total number $k_{i}=q_{i} l_{i}$ of train kilometers, where $q_{i}$ is the frequency of service, and $l_{i}$ is the length of the line in kilometers). First, note that the costs of using infrastructure are the access charges that have to be paid to DB Netz. These costs differ across lines. We have detailed information on these access costs for each line. Let $a_{i}$ be the access charge for a line. We calculated the detailed access prices for 504 out of the 551 lines, or $91 \%$, of the lines observed in our sample (the percentage with information on access price is $92 \%$ on lines that were negotiated with the incumbent). For the remaining 47 lines we could not match the start and end station with the data base providing information on access prices. We impute missing access prices using linear regression.

Second, for simplicity, we suppose that the remaining costs of running the service are identical on the different lines but they differ across German states. Let $x_{j}$ denote the remaining costs of running the service, with $j=1, \ldots, J$ indexing German states (Bundesländer). The resulting negotiation price is

$$
t_{i}^{N}=a_{i}+x_{j}
$$

We also use information on the average negotiation price by state $p_{j}$. We estimate $x_{j}$ assuming that the average (frequency of service weighted) negotiation price is identical to the state level negotiation price. Let $b_{i j}=1$ if line $i$ is situated in state $j$, and $b_{i j}=0$ otherwise, and $D_{i}=1$ if the line is auctioned, and $D_{i}=0$ otherwise. It follows that

$$
p_{j}=\frac{\sum_{i}^{I} b_{i j}\left(1-D_{i}\right) k_{i}^{N} t_{i}^{N}}{\sum_{i}^{I} b_{i j}\left(1-D_{i}\right) k_{i}^{N}}
$$

this means we can back out an estimate of the state specific cost of running the service is

$$
x_{j}=\frac{p_{j} \sum_{i}^{I} b_{i j}\left(1-D_{i}\right) k_{i}^{N}\left(p_{j}-a_{i}\right)}{\sum_{i}^{I} b_{i j}\left(1-D_{i}\right) k_{i}^{N}}
$$

The resulting negotiation prices $t_{i}^{N}$ have a number of properties. First, the state average negotiation prices match the quoted prices exactly. Second, the resulting negotiation price components match published sources well. The average total negotiation price was 8.73 Euro per train kilometer, with the access charge amounting to 3.53 Euro on average. Thus, the access charge makes up $40 \%$ of the total price. According to LNVG (2010), infrastructure costs amount to about $40 \%$ of the costs of railway services. 
Figure 1: Frequency of Service by Procurement Mode, in 2004

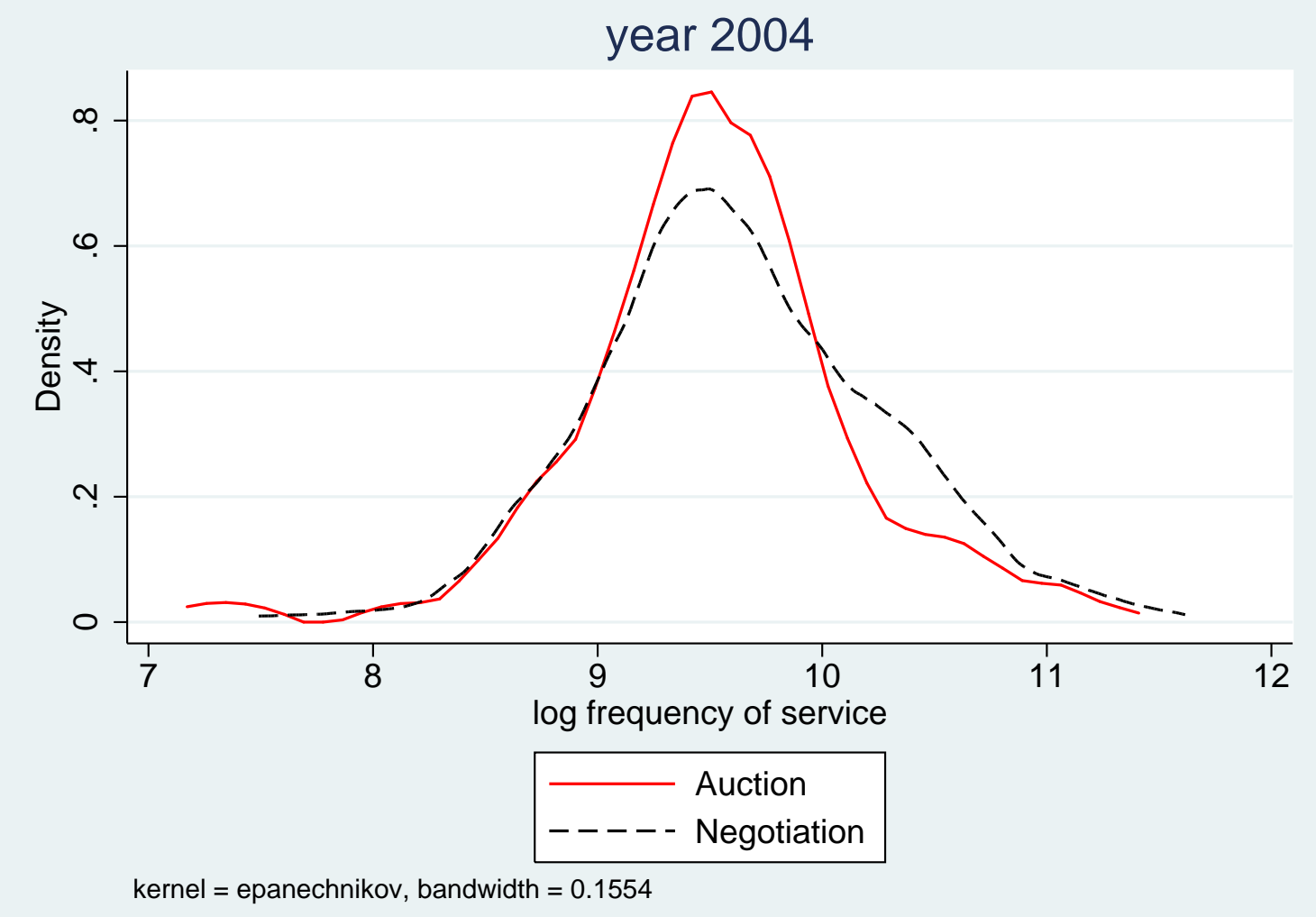

Notes: Figure displays log train kilometers per line kilometers in the timetable year 2003/2004. Auction means the services on the line were auctioned between 1994 and 2004. Negotiation means the services on the line were negotiated between the incumbent supplier and the regional transport agency.

Source: Own calculations. 
Figure 2: Growth in Frequency of Service, 1994 to 2004

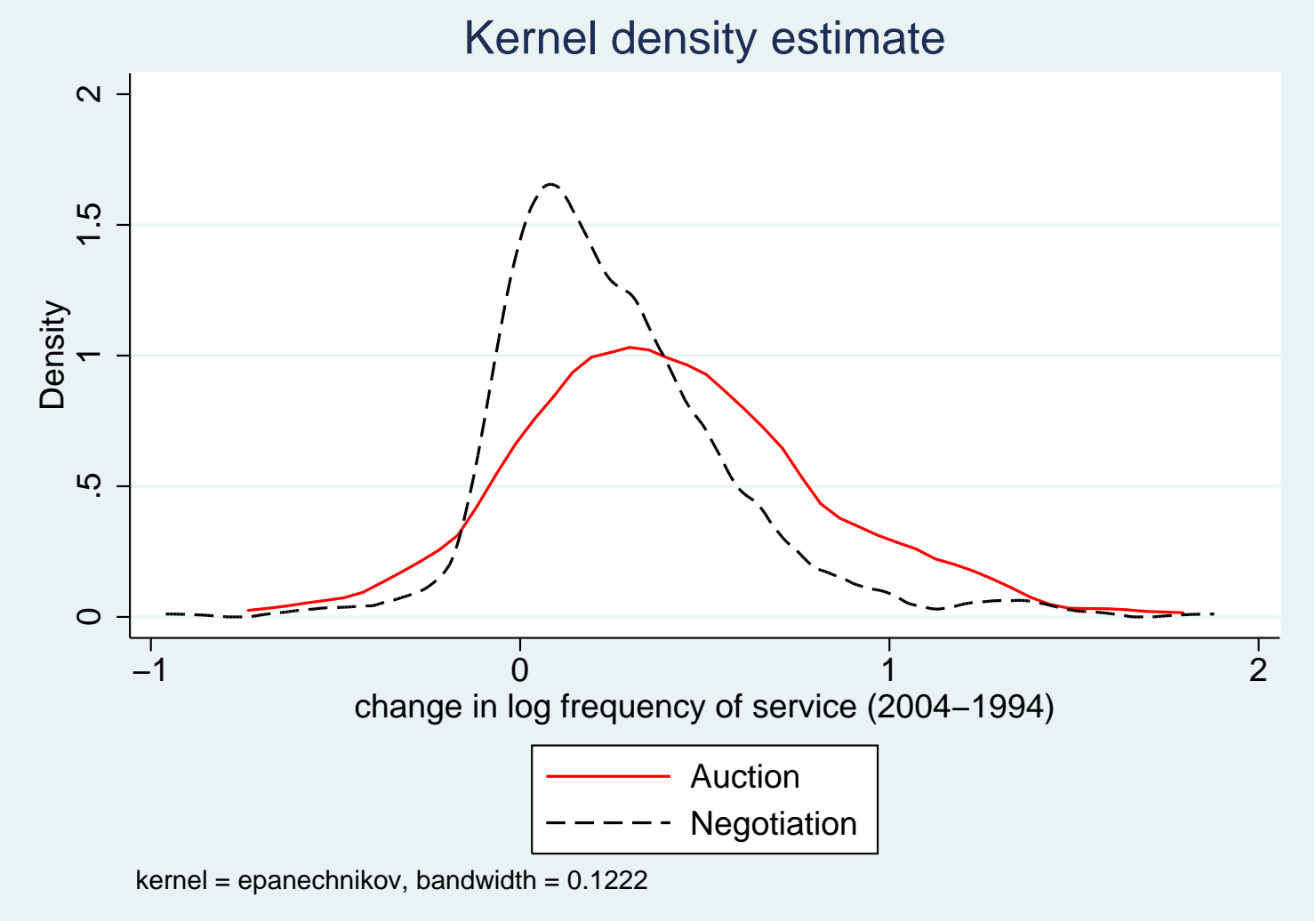

Notes: Growth in frequency of service is the change in log frequency of service from 1994 to 2004. Auction means the services on the line were auctioned between 1994 and 2004. Negotiation means the services on the line were negotiated between the incumbent supplier and the regional transport agency.

Source: Own calculations. 
Figure 3: Net Agency Surplus Gain Due to Auction

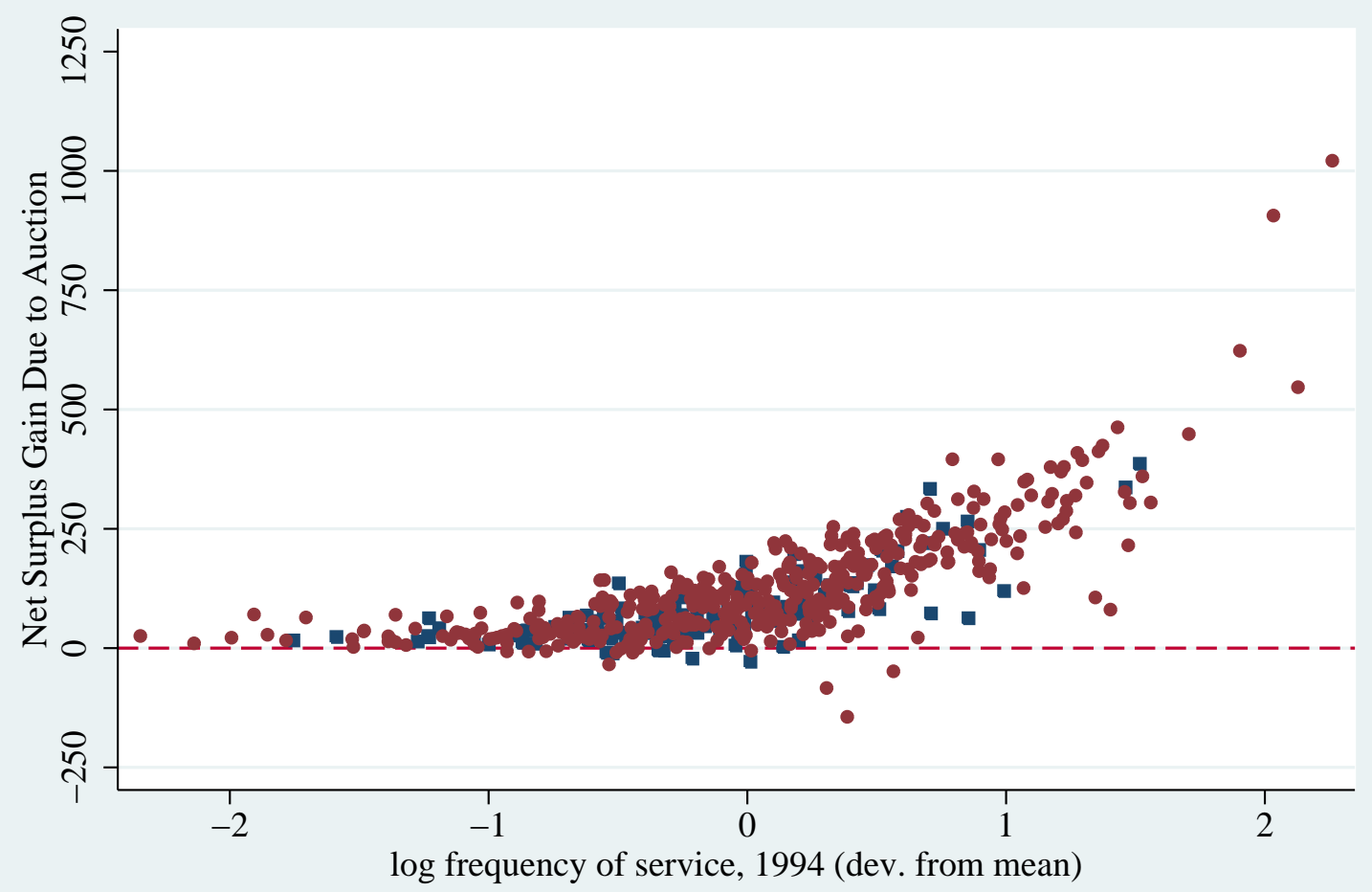

- Auctioned Negotiated

Notes: Net agency surplus refers to surplus net of transfer payments on regional passenger train lines (in Euros per calendar day). Agency surplus gain is net agency surplus supposing a line is auctioned subtracting net agency surplus supposing services on a line are directly negotiated with the incumbent.

Source: Own calculations, based on estimates reported in Table 7. 
Table 1: Comparison of Means by Procurement Mode

\begin{tabular}{lccccc}
\hline \hline & Auction & Negotiation & Difference & Std Err & t-Stat \\
\hline log frequency, 2004 & 9.528 & 9.612 & -0.084 & 0.062 & -1.361 \\
log frequency, 1994 & 9.139 & 9.363 & -0.224 & 0.059 & -3.799 \\
incumbent & 0.196 & 0.932 & -0.737 & 0.036 & -20.412 \\
net contract & 0.673 & .932 & -0.258 & .035 & -7.38 \\
& & & & & \\
electric traction & 0.246 & 0.523 & -0.277 & 0.044 & -6.247 \\
distance to city (km) & 24.138 & 15.700 & 8.438 & 3.303 & 2.555 \\
log track length & 3.774 & 3.818 & -0.044 & 0.081 & -0.543 \\
log pop largest city & 4.534 & 5.178 & -0.644 & 0.141 & -4.575 \\
log pop 2nd largest city & 3.072 & 3.481 & -0.409 & 0.133 & -3.086 \\
& & & & & \\
Observations & 138 & 413 & & & \\
\hline \hline
\end{tabular}

Notes: Date provides information on 551 regional passenger railway lines. Auction means the services on the line were auctioned between 1994 and 2004. Negotiation means the services on the line were negotiated between the incumbent supplier and the regional transport agency. Log frequency refers to train kilometers per line kilometers. Incumbent means services on the line were supplied by the incumbent service provider $(D B$ Regio $)$. Net contract $=1$ means the train operator receives the revenues, whereas net contract $=0$ means train operator does not receive fare revenues. Distance to city measures the distance of the line to a city with more than 100,000 inhabitants in 2004. log pop largest city is the log of the number of inhabitants of the largest city in 1994 along the line. log pop 2nd largest city refers to the number of inhabitants of the second largest city in 1994 along the line.

Source: Own calculations, German Statistical Office. 
Table 2: Quantity before Procurement

\begin{tabular}{lcc}
\hline \hline & base & controls \\
auctioned & $-0.224^{* *}$ & -0.015 \\
& $(0.099)$ & $(0.050)$ \\
electric traction & & $0.367^{* * *}$ \\
& & $(0.046)$ \\
distance to city $(\mathrm{km})$ & & $-0.004^{* * *}$ \\
& & $(0.001)$ \\
log track length & & $-0.112^{*}$ \\
& & $(0.061)$ \\
log pop largest city & & 0.052 \\
& & $(0.038)$ \\
log pop 2nd largest city & & $0.112^{* * *}$ \\
& & $(0.028)$ \\
Constant & $9.363^{* * *}$ & $9.311^{* * *}$ \\
& $(0.079)$ & $(0.043)$ \\
adj-R-Sq & 0.018 & 0.329 \\
Observations & 551 & 551 \\
\hline
\end{tabular}

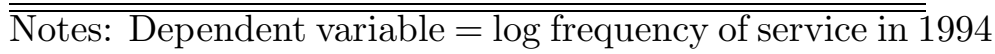
(before Regionalisierungsgesetz). Cluster robust standard errors (clustered on agencies).

Source: Own calculations. 
Table 3: Explaining Procurement Mode

\begin{tabular}{lcc}
\hline \hline & base & agency \\
log frequency & -0.008 & -0.007 \\
& $(0.027)$ & $(0.029)$ \\
electric traction & $-0.174^{* * *}$ & $-0.168^{* * *}$ \\
& $(0.061)$ & $(0.053)$ \\
distance to city $(\mathrm{km})$ & -0.000 & 0.001 \\
& $(0.001)$ & $(0.001)$ \\
log track length & 0.023 & -0.009 \\
& $(0.024)$ & $(0.030)$ \\
log pop largest city & -0.033 & -0.010 \\
& $(0.023)$ & $(0.030)$ \\
log pop 2nd largest city & 0.009 & 0.016 \\
& $(0.017)$ & $(0.020)$ \\
Constant & 0.329 & $0.785^{* * *}$ \\
& $(0.246)$ & $(0.270)$ \\
adj-R-Sq & 0.056 & 0.176 \\
Observations & 551 & 551 \\
\hline
\end{tabular}

Notes: Dependent variable is 1 if the regional passenger line was procured by auction and it is 0 if the line was procured by negotiation with the incumbent Deutsche Bahn. Linear probability model. Cluster robust standard errors (clustered on regional passenger service agency). F-statistic for joint significance of agencies is $708.72(p<.001)$.

Source: Own calculations. 
Table 4: Procurement and Quantity

\begin{tabular}{|c|c|c|c|c|}
\hline \multirow{3}{*}{ auctioned } & base & "interactions & $\overline{\text { joint }}$ & match \\
\hline & $0.132^{* * *}$ & $0.149^{* * *}$ & 0.136 & $0.166^{* *}$ \\
\hline & $(0.045)$ & $(0.051)$ & $(0.102)$ & $(0.079)$ \\
\hline \multirow{2}{*}{$\log$ frequency } & $0.778 * * *$ & $0.801^{* * *}$ & $0.801^{* * *}$ & \\
\hline & $(0.027)$ & $(0.036)$ & $(0.047)$ & \\
\hline \multirow[t]{2}{*}{ electric traction } & $0.056^{*}$ & $0.054^{*}$ & 0.051 & \\
\hline & $(0.031)$ & $(0.031)$ & $(0.043)$ & \\
\hline \multirow[t]{2}{*}{ distance to city $(\mathrm{km})$} & -0.001 & -0.001 & -0.001 & \\
\hline & $(0.001)$ & $(0.001)$ & $(0.001)$ & \\
\hline \multirow[t]{2}{*}{ log track length } & $-0.089^{* * *}$ & $-0.066^{* * *}$ & $-0.065^{* * *}$ & \\
\hline & $(0.014)$ & $(0.022)$ & $(0.023)$ & \\
\hline \multirow[t]{2}{*}{ log pop largest city } & 0.025 & 0.004 & 0.003 & \\
\hline & $(0.016)$ & $(0.014)$ & $(0.018)$ & \\
\hline \multirow[t]{2}{*}{ log pop 2nd largest city } & 0.022 & 0.017 & 0.017 & \\
\hline & $(0.014)$ & $(0.013)$ & $(0.014)$ & \\
\hline \multirow[t]{2}{*}{ auction $* \log$ frequency } & & $-0.135^{*}$ & -0.134 & \\
\hline & & $(0.078)$ & $(0.100)$ & \\
\hline \multirow[t]{2}{*}{ auction $*$ el. tract. } & & 0.026 & 0.027 & \\
\hline & & $(0.084)$ & $(0.090)$ & \\
\hline \multirow[t]{2}{*}{ auction $*$ dist. to city } & & 0.001 & 0.001 & \\
\hline & & $(0.002)$ & $(0.002)$ & \\
\hline \multirow[t]{2}{*}{ auction $* \log$ length } & & -0.085 & -0.085 & \\
\hline & & $(0.068)$ & $(0.056)$ & \\
\hline \multirow[t]{2}{*}{ auction $* \log$ pop largest city } & & $0.090^{* *}$ & $0.091^{*}$ & \\
\hline & & $(0.043)$ & $(0.047)$ & \\
\hline \multirow[t]{2}{*}{ auction $* \log$ pop 2 nd largest city } & & 0.020 & 0.020 & \\
\hline & & $(0.039)$ & $(0.046)$ & \\
\hline \multirow[t]{2}{*}{ auction $*$ residual (agency) } & & & -0.001 & \\
\hline & & & $(0.205)$ & \\
\hline \multirow{2}{*}{ residual (agency) } & & & 0.017 & \\
\hline & & & $(0.121)$ & \\
\hline \multirow[t]{2}{*}{ Constant } & $9.558^{* * *}$ & $9.559^{* * *}$ & $9.563^{* * *}$ & \\
\hline & $(0.024)$ & $(0.024)$ & $(0.028)$ & \\
\hline adj-R-Sq & 0.747 & 0.749 & & \\
\hline Observations & 551 & 551 & 551 & 551 \\
\hline
\end{tabular}

Notes: Dependent variable $=\log$ frequency of service in 2004 (after Regionalisierungsgesetz). Columns "base" and "interactions" report least squares estimates with cluster robust standard errors (clustered on agency). Column "joint" models decision to auction and quantity jointly. "Residual (agency)" is the residual from procurement choice (model "agencies" in Table 3) and the interaction term "Auction * residual (agency)" is the (sample mean centered) residual (bootstrap standard errors with 1000 replications, clustered at agency level). Column "match" reports mahalanobis (i.e. inverse variance weighted) nearest neighbor matching results (bootstrap standard errors with 100 replications, clustered at agency level).

Source: Own calculations. 
Table 5: Procurement and Subsidy Price

\begin{tabular}{|c|c|c|c|c|}
\hline auctioned & $\begin{array}{c}\text { base } \\
-0.253^{* * *} \\
(0.043)\end{array}$ & $\begin{array}{c}\text { interactions } \\
-0.293^{* * *} \\
(0.048)\end{array}$ & $\begin{array}{c}\text { joint } \\
-0.212 \\
(0.152)\end{array}$ & $\begin{array}{c}\text { match } \\
-0.282^{* * *} \\
(0.065)\end{array}$ \\
\hline $\log$ frequency & $\begin{array}{l}-0.025 \\
(0.016)\end{array}$ & $\begin{array}{c}-0.030^{*} \\
(0.016)\end{array}$ & $\begin{array}{c}-0.031^{*} \\
(0.018)\end{array}$ & \\
\hline electric traction & $\begin{array}{c}0.004 \\
(0.019)\end{array}$ & $\begin{array}{c}0.017 \\
(0.019)\end{array}$ & $\begin{array}{c}0.008 \\
(0.026)\end{array}$ & \\
\hline distance to city (km) & $\begin{array}{c}-0.001^{*} \\
(0.001)\end{array}$ & $\begin{array}{c}-0.001 * \\
(0.001)\end{array}$ & $\begin{array}{l}-0.001 \\
(0.001)\end{array}$ & \\
\hline log track length & $\begin{array}{l}-0.008 \\
(0.013)\end{array}$ & $\begin{array}{l}-0.005 \\
(0.012)\end{array}$ & $\begin{array}{l}-0.004 \\
(0.013)\end{array}$ & \\
\hline log pop largest city & $\begin{array}{l}-0.010 \\
(0.011)\end{array}$ & $\begin{array}{l}-0.007 \\
(0.011)\end{array}$ & $\begin{array}{l}-0.009 \\
(0.013)\end{array}$ & \\
\hline log pop 2nd largest city & $\begin{array}{l}-0.010 \\
(0.009)\end{array}$ & $\begin{array}{l}-0.005 \\
(0.011)\end{array}$ & $\begin{array}{l}-0.004 \\
(0.010)\end{array}$ & \\
\hline net & $\begin{array}{c}0.058 \\
(0.051)\end{array}$ & $\begin{array}{c}0.033 \\
(0.037)\end{array}$ & $\begin{array}{c}0.036 \\
(0.060)\end{array}$ & \\
\hline auction $* \log$ frequency & & $\begin{array}{c}0.062 \\
(0.047)\end{array}$ & $\begin{array}{c}0.063 \\
(0.072)\end{array}$ & \\
\hline auction $*$ el. tract. & & $\begin{array}{c}-0.154^{* *} \\
(0.060)\end{array}$ & $\begin{array}{l}-0.136 \\
(0.089)\end{array}$ & \\
\hline auction $*$ dist. to city & & $\begin{array}{l}-0.001 \\
(0.001)\end{array}$ & $\begin{array}{l}-0.001 \\
(0.002)\end{array}$ & \\
\hline auction $* \log$ length & & $\begin{array}{c}0.017 \\
(0.027)\end{array}$ & $\begin{array}{c}0.014 \\
(0.041)\end{array}$ & \\
\hline auction $* \log$ pop largest city & & $\begin{array}{l}-0.056 \\
(0.041)\end{array}$ & $\begin{array}{l}-0.052 \\
(0.056)\end{array}$ & \\
\hline auction $* \log$ pop 2 nd largest city & & $\begin{array}{l}-0.064 \\
(0.057)\end{array}$ & $\begin{array}{l}-0.065 \\
(0.067)\end{array}$ & \\
\hline auction $*$ residual & & & $\begin{array}{l}-0.200 \\
(0.277)\end{array}$ & \\
\hline residual & & & $\begin{array}{c}0.056 \\
(0.199)\end{array}$ & \\
\hline Constant & $\begin{array}{c}2.102^{* * *} \\
(0.046)\end{array}$ & $\begin{array}{c}2.123^{* * *} \\
(0.027)\end{array}$ & $\begin{array}{c}2.132^{* * *} \\
(0.058)\end{array}$ & \\
\hline adj-R-Sq & 0.276 & 0.345 & & \\
\hline Observations & 476 & 476 & 476 & 476 \\
\hline
\end{tabular}

Notes: Dependent variable $=\log$ price in 2004 (after Regionalisierungsgesetz). Columns "base" and "interactions" report least squares estimates with cluster robust standard errors (clustered on agency). Column "joint" models decision to auction and price jointly. "Residual (agency)" is the residual from procurement choice (model "agencies" in Table 3) and the interaction term "Auction * residual (agency)" is the (sample mean centered) residual (bootstrap standard errors with 1000 replications, clustered at agency level). Column "match" reports mahalanobis (i.e. inverse variance weighted) nearest neighbor matching results (bootstrap standard errors with 100 replications, clustered at agency level).

Source: Own calculations. 
Table 6: Explaining Auction Effects: Demand vs Ownership

\begin{tabular}{lccccc}
\hline \hline & pop1 & pop2 & incumbent & quantity & price \\
auctioned & 0.003 & -0.009 & $-0.714^{* * *}$ & $0.142^{* * *}$ & $-0.265^{* * *}$ \\
& $(0.013)$ & $(0.018)$ & $(0.060)$ & $(0.050)$ & $(0.074)$ \\
log frequency & 0.006 & $0.018^{*}$ & 0.030 & $0.779^{* * *}$ & -0.024 \\
& $(0.004)$ & $(0.010)$ & $(0.029)$ & $(0.028)$ & $(0.015)$ \\
electric traction & 0.004 & 0.000 & 0.013 & $0.055^{*}$ & 0.002 \\
& $(0.011)$ & $(0.016)$ & $(0.052)$ & $(0.030)$ & $(0.020)$ \\
distance to city $(\mathrm{km})$ & -0.000 & $-0.001^{* *}$ & -0.000 & -0.001 & $-0.001^{*}$ \\
& $(0.000)$ & $(0.000)$ & $(0.001)$ & $(0.001)$ & $(0.001)$ \\
log track length & -0.007 & -0.011 & 0.031 & $-0.089^{* * *}$ & -0.006 \\
& $(0.007)$ & $(0.009)$ & $(0.027)$ & $(0.014)$ & $(0.013)$ \\
log pop largest city & $0.996^{* * *}$ & -0.005 & 0.003 & 0.025 & -0.011 \\
& $(0.005)$ & $(0.007)$ & $(0.019)$ & $(0.016)$ & $(0.011)$ \\
log pop 2nd largest city & -0.002 & $0.961^{* * *}$ & 0.016 & 0.022 & -0.012 \\
& $(0.004)$ & $(0.020)$ & $(0.013)$ & $(0.014)$ & $(0.010)$ \\
auction * incumbent & & & & -0.049 & -0.014 \\
& & & & $(0.047)$ & $(0.094)$ \\
Constant & $4.942^{* * *}$ & $3.215^{* * *}$ & $0.652^{* *}$ & $2.311^{* * *}$ & $2.382^{* * *}$ \\
adj-R-Sq & $(0.043)$ & $(0.097)$ & $(0.279)$ & $(0.259)$ & $(0.160)$ \\
Observations & 0.998 & 0.988 & 0.555 & 0.746 & 0.267 \\
\hline \hline
\end{tabular}

Notes: Dependent variables: pop1 is log population of largest city, pop2 is log population of second largest city, incumbent takes the value 1 if Deutsche Bahn operates the services on the line, and the value 0 otherwise, and owner has frequency of service in 2004 as the dependent variable. Standard errors clustered at agency level.

Source: Own calculations. 
Negotiation price $(\nu)$

$\log$ frequency of service, 1994

electric traction

distance to city $(\mathrm{km})$

log track length

log pop in largest city

log pop in 2nd largest city

intercept

Auction price change ( $\alpha$ )

$\log$ frequency of service, 1994

electric traction

distance to city $(\mathrm{km})$

log track length

$\log$ pop in largest city

log pop in 2nd largest city

intercept

Incumbent negotiation power ( $\pi$ )

$\log$ frequency of service, 1994

electric traction

distance to city $(\mathrm{km})$

log track length

log pop in largest city

log pop in 2nd largest city

intercept

Incumbent auction power ( $\beta$ )

$\log$ frequency of service, 1994

electric traction

distance to city $(\mathrm{km})$

log track length

log pop in largest city

log pop in 2nd largest city

intercept

Consumer surplus ( $\sigma$ )

$\log$ frequency of service, 1994

electric traction

distance to city $(\mathrm{km})$

log track length

log pop in largest city

log pop in 2nd largest city

intercept
Coef. Std. Err. z

$\begin{array}{lll}-0.031 & 0.015 & -2.01\end{array}$

$\begin{array}{lll}0.016 & 0.019 \quad 0.87\end{array}$

$\begin{array}{lll}-0.001 & 0.001 & -1.92\end{array}$

$\begin{array}{lll}-0.004 & 0.012 & -0.32\end{array}$

$\begin{array}{lll}-0.007 & 0.011 & -0.69\end{array}$

$\begin{array}{lll}-0.006 & 0.011 & -0.54\end{array}$

$2.154 \quad 0.034 \quad 64.15$

$\begin{array}{ccc}0.078 & 0.047 & 1.67 \\ -0.159 & 0.062 & -2.57 \\ -0.001 & 0.001 & -0.70 \\ 0.019 & 0.028 & 0.68 \\ -0.055 & 0.041 & -1.35 \\ -0.071 & 0.055 & -1.29 \\ -0.302 & 0.053 & -5.65\end{array}$

$\begin{array}{lll}-0.057 & 0.091 & -0.63\end{array}$

$\begin{array}{lll}-0.133 & 0.104 & -1.28\end{array}$

$\begin{array}{lll}0.000 & 0.003 & 0.06\end{array}$

$\begin{array}{lll}-0.066 & 0.073 & -0.91\end{array}$

$\begin{array}{lll}0.036 & 0.059 & 0.60\end{array}$

$\begin{array}{lll}-0.050 & 0.067 & -0.75\end{array}$

$\begin{array}{lll}-0.153 & 0.074 & -2.07\end{array}$

$\begin{array}{ccc}0.128 & 0.106 & 1.20 \\ -0.193 & 0.133 & -1.46 \\ 0.000 & 0.003 & -0.15 \\ 0.075 & 0.084 & 0.90 \\ -0.100 & 0.078 & -1.29 \\ -0.005 & 0.089 & -0.05 \\ 0.102 & 0.091 & 1.12\end{array}$

$\begin{array}{lll}0.713 & 0.099 & 7.20\end{array}$

$\begin{array}{lll}-0.063 & 0.111 & -0.57\end{array}$

$\begin{array}{lll}-0.002 & 0.003 & -0.71\end{array}$

$\begin{array}{lll}-0.136 & 0.077 & -1.76\end{array}$

$\begin{array}{lll}0.032 & 0.062 & 0.52\end{array}$

$\begin{array}{lll}-0.039 & 0.069 & -0.57\end{array}$

$\begin{array}{lll}11.560 & 0.085 & 136.57\end{array}$

Notes: Table displays structural parameters of the theoretical model (see Section 5). Coef. refers to estimated parameter, Std. Err. to estimated standard error (clustered by agency), and $\mathrm{z}$ is the asymptotic test statistic for the null of the parameter not being different from zero. Source: Own calculations. 
Table 8: Effects on Cost, Surplus, and Net Agency Surplus

\begin{tabular}{lccc}
\hline \hline & $\begin{array}{c}\text { A. Negotiation } \\
\text { actual }\end{array}$ & $\begin{array}{c}\text { B. Auction } \\
\text { Frequency of service (tkm per lkm) }\end{array}$ & $\begin{array}{c}\text { C. Negotiation } \\
\text { no power }\end{array}$ \\
Transfer price (EUR per tkm) & 46.43 & 53.66 & 38.25 \\
& & $(15.57)$ & $(-17.62)$ \\
Transfer payments (EUR) & 8.62 & 6.47 & 8.62 \\
& & $(-24.94)$ & $(0.00)$ \\
& 397.20 & 327.54 & 327.54 \\
Surplus (EUR) & & $(-17.54)$ & $(-17.54)$ \\
& & $\{-17.54\}$ & $\{-17.54\}$ \\
Net agency surplus (EUR) & & 3276.71 & 3170.64 \\
& & $(1.42)$ & $(-1.87)$ \\
& & $\{11.53\}$ & $\{-15.17\}$ \\
Observations & & & 2843.09 \\
\hline
\end{tabular}

Notes: Table displays frequency of service, transfer price, gross surplus, cost, and net agency surplus per calendar day (i.e. dividing annual outcomes by 365) for all regional passenger lines in the sample. Column A shows outcomes assuming that all lines were negotiated with the incumbent. Column B shows outcomes due to auctions. Column $\mathrm{C}$ shows outcomes of negotiations where the incumbent's negotiation power $\left(P_{i}\right)$ is set to zero. Percentage change compared to outcome in negotiation in parentheses. Percentage change in net surplus components relative to transfer payments if lines are negotiated in curly brackets. tkm is train kilometers, $1 \mathrm{~km}$ is line kilometers.

Source: Own calculations, based on parameters in Table 7. 